Business Writing Style Guide 



\title{
Business Writing Style Guide
}

\author{
JOHN MORRIS AND JULIE ZWART
}

OPEN EDUCATIONAL RESOURCES: OREGON STATE UNIVERSITY CORVALLIS, OR 


\section{(ㄷ) (1) () (2)}

Business Writing Style Guide by John Morris \& Julie Zwart is licensed under a Creative Commons Attribution-NonCommercial-ShareAlike 4.0 International License, except where otherwise noted.

Publication and ongoing maintenance of this textbook is possible due to grant support from Oregon State University Ecampus.

Suggest a correction (bit.ly/33cz3Q1)

Privacy (open.oregonstate.education/privacy)

This book was produced with Pressbooks (https://pressbooks.com) and rendered with Prince. 


\section{Contents}

Introduction 1

What, me worry?

What is Good Writing?

The Power of Words $\quad 5$

Continuous Improvement $\quad 6$

$\begin{array}{ll}\text { Our Motivation for this Book } & 7\end{array}$

The Writing Process $\quad 8$

$\begin{array}{ll}\text { Writing a Report for Business } & 8\end{array}$

$\begin{array}{ll}\text { The 3-part Writing Process } & 12\end{array}$

A Standard Essay Template 31

Writing Essentials $\quad 34$

Formatting a Business Report 34

Understanding Assignment Requirements 37

Thesis statements $\quad 46$

$\begin{array}{ll}\text { Keeping writing honest and avoiding plagiarism } & 47\end{array}$

$\begin{array}{ll}\text { Writing for Persuasion } & 50\end{array}$

$\begin{array}{ll}\text { Grammar } & 57\end{array}$

$\begin{array}{ll}\text { Writing Concisely } & 71\end{array}$

$\begin{array}{ll}\text { Tables and Figures } & 78\end{array}$

$\begin{array}{ll}\text { Appendices - A Note on End Matter } & 79\end{array}$

Actionable Recommendations $\quad 79$ 
Writing and Business Models

Why Use a Model?

Example 1-SWOT

Example 2 - Porter's Five Forces $\quad 91$

Example 3 - BEP Analysis 998

What if I Have to Present? 104

$\begin{array}{ll}\text { Feedback and Grading } & 108\end{array}$

$\begin{array}{ll}\text { Rubrics } & 108\end{array}$

Key to Common Markups (and how to fix them) 112

Resources For Getting Better $\quad 115$

Exercises for Getting Better 116

$\begin{array}{ll}\text { Acknowledgements } & 123\end{array}$

$\begin{array}{ll}\text { Works Cited } & 126\end{array}$

$\begin{array}{ll}\text { Creative Commons License } & 128\end{array}$

$\begin{array}{ll}\text { Recommended Citations } & 129\end{array}$

$\begin{array}{ll}\text { Versioning } & 132\end{array}$ 


\section{Introduction}

We are all apprentices in a craft where no one ever becomes a master. Ernest Hemingway

It is the goal of this book to help students do the following:

- Apply basic concepts for effective and concise business writing.

- Compile a well written report acceptable within a business context.

- Follow a writing process designed for business students.

- Demonstrate critical thinking, reasoning, and persuasion.

- Communicate in writing using a business model.

- Apply resources for improving business writing skills.

Chapter 1 should help the reader understand why writing is important in business and in the educational process leading up to a career in business. We'll spell out what good writing looks like, the power of using the correct words, and the importance of continuous improvement.

\section{What, me worry?}

Most college students won't enter the workplace as CEO or general manager (GM) of a business. Indeed, it may be several decades before you take on such a broad and generalized role. Still, having the GM's perspective of running a business allows you to be more effective regardless of where you sit in the organization's hierarchy. Even if you never achieve the top position in a corporate structure, knowing what these managers and leaders are dealing with and the 
issues they face helps to remove the mystery of why they make the choices and decisions they do.

As a new college graduate, the most probable role you will play is as an analyst. The title may be different-management trainee, consultant, accountant, marketing specialist, etc.-but the task will often involve digging into a pile of raw data, making sense out of it, and then communicating what you know to somebody else.

For many, writing a report is one of the most difficult aspects of the position of analyst. This book contains one approach to reducing the stress and challenge of such a task. Consider that the process is typically done in three stages following the organization of the next chapter: 1) analyze the situation, 2) write the report (or prepare a set of slides), and 3) edit. You are strongly encouraged to take these as unique but interconnected phases of the same process. That is, as you shift from one phase to the next, the focus of your work will change, but the ultimate end-point remains the same.

\section{What is Good Writing?}

Writing is not a science; there are few similarities between crafting a masterful business report and designing a scientific experiment. In this regard, writing is more of an art. But just like art has its "rule of thirds" (a principle that helps artists choose the placement of objects within a composition to maximize aesthetics), writing has similar guidelines to help writers make the most of their efforts. To go one step further, colleges are required to teach students how to write-in-their-profession. With this in mind, the following concepts will not only help you to write effectively in the profession of business, they will help you to demonstrate mastery as a business student. At one level, everything that follows in this book will provide deeper and finer detail on these three concepts. 


\section{Be Concise}

One of the hardest things about writing in business is being concise. Doing so, however, will mark you as a savvy business professional. This means while you always want to answer the question fully, you omit everything that is unnecessary, regardless of how interesting it is. It may feel difficult to spend minutes or hours crafting a clever, insightful, and technically accurate passage only to delete it from your report, but your report will be better for it. Before you consider yourself done with a report, step away for a brief period, reread the report and consider whether the document clearly and succinctly answers the question you were asked.

\section{Be Complete}

Managers know about the power of a well-written executive summary. We put them at the beginning of the report but write them last. An executive summary needs to be accurate and concise; it should capture the totality of the report in one or a few paragraphs no matter the length of the report. In other words, the executive summary of a 100-page white paper and a 10-page summary analysis will still provide the same style-and possibly same length-of high level overview based on the contents of the report.

This doesn't mean executives don't want details. It means they want the story wrapped up tightly so they can prioritize the report's content before they dig into it. Get to the point quickly, layout your analytical framework, and then explore the details of your analysis. If you have lots of data, graphs, tables, and charts, include them as clearly labeled figures and reference them in your report. For more information on how to handle large volumes of related, or possibly tangential material, see the section on Appendices. 
To be complete in a business school context, include references to specific models from your course, show your calculations (complete with units of measure), and cite your sources. Equally important as having the data, is to identify and report your assumptions. Sometimes, you simply don't have all the data you need so you have to make assumptions to complete your analysis. Clearly reporting your assumptions will allow your manager, client, or instructor to know how you got from a set of data or ideas to a specific conclusion.

\section{Use Essential Vocabulary}

Regardless of the field, the vocabulary someone uses quickly distinguishes a novice from an expert. Every profession-medicine, law, sports, music, and business-has its own unique set of specialized lexicon; your ability to use the right terms and concepts appropriately sets you apart from everyone else.

If you know the thrill of holing out from the rough on a blind approach to put you three up with two to go, or if you know the pain of receiving a cross in the box, beating the keeper, and clanging a header off the bar, you may have spent too much time on a golf links or soccer pitch, respectively. Similarly, if you claim the board destroyed shareholder value by wasting corporate resources and poisoning shareholder relationships, you will capture the attention of a hiring manager; and you had better be prepared to back it up with hard data!

In business, you don't get much leeway when you use a business term incorrectly and you'll be instantly branded an outsider or greenhorn. In school, you have a distinct advantage in that most instructors will provide the essential vocabulary you should master during the course. To demonstrate mastery of the topic, use that terminology when writing reports and responding to assignment prompts. School is your opportunity to try out this terminology in 
a learning environment, where mistakes can easily be corrected and have no long-term implications.

\section{The Power of Words}

British author, Edward George Bulwer-Lytton, is credited with the expression "the pen is mightier than the sword". Indeed, words have the power to shape how we see the world and understanding this point is critical in writing and in life. In creating this textbook, we gained insight into the unique vocabulary we had developed as instructors. These words essentially shape the way we see the profession of teaching and using writing in teaching, so we want to call them out before going further.

Earn vs. Award. It is our belief that assignment and course grades, especially when evaluated using rubrics, are "earned" not "awarded". This may seem to some students like "splitting hairs", but in both course and assignment design this orientation toward "earning" focuses the locus of control squarely on the student.

Report vs. Paper/Essay. Although these terms may show up as synonyms in this textbook, we have a bias for "report". Mostly, this is because of its use outside of academia. True, all are interchangeable, but business people are more likely to speak about reports than papers (except in the context of a "white paper"). Most certainly as a professional in the work world you are very unlikely to be assigned to write an essay.

Score vs. Grade. We use the terms "grade" and "score" interchangeably in the textbook as it relates to assignments. At times, you will see a slight bias toward using "score" in reference to assessing an assignment and "grade" in reference to a course. This bias derives from the pragmatic reality that the grade is the end result of a term's worth of work, therefore, scores are what builds up to that end result.

Assignment vs. Prompt. These two terms are used 
interchangeably throughout the book. As with most languages, some subtle conventions may call for one over the other, but those distinctions are not intended to be relevant in this project. When you encounter either of these terms-or these terms used in combination with "description" and "assigned"-you can consider them to refer to the work the instructor wants from the student.

$\mathrm{He}$, She, or They. There is a growing awareness in global business and education communities around gender (and other) diversity. While there is some change afoot, it is not yet official within the APA and related circles. In this textbook we have chosen to use the pronoun "they" and "their" in place of "he" or "she" or the awkward "he and she", "he/she", "s/he" except where it makes sense grammatically. Our decision is a style choice only and should not be interpreted as a writing rule, at least not yet. An astute student may consider asking their instructor before repeating this practice in case they have a preference.

\section{Continuous Improvement}

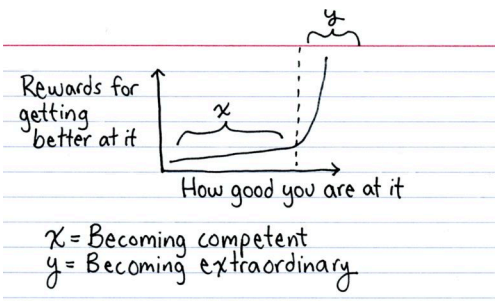

Figure 1.1 - Practice Makes Legacy. Used with Permission from Indexed(C) Jessica Hagy, granted 7/25/2018
There's a story, which is often told in foundational business courses, about why in the 1980s Toyota was able to produce some of the most reliable cars in the world and why American companies, like General Motors, were unable to achieve the reliability and reputation that Toyota had gained.

Toyota's story is one of kaizen, which translates to continuous improvement. It's something that was built into the company culture, the idea of always striving to get better. In a Toyota factory, 
if a worker on the assembly line saw a problem-a part in the wrong place, or missing-they would stop the line and fix it. Meanwhile, in GM factories, problems were ignored and dealt with later, so the factory could produce as many cars as possible in a given day. Toyota was successful because continuous improvement was built into the company culture, whereas at GM it was not. Continuous improvement is about not letting things "slide" because of laziness, indifference, or being hurried. It is about fixing mistakes and making improvements in the moment. In writing, having the mindset of continuous improvement makes us better writers.

Becoming a strong writer is a skill that takes a lifetime to develop and refine. It is a journey you started in elementary school and will continue to hone as you progress along your career path. But, continued progress is not a guarantee. It takes effort and awareness to continuously improve. As a student of business, if your aspiration is to rise in a professional or managerial hierarchy, you must be a good writer. The overriding goal of this writing guide is to help you along your journey as a writer.

\section{Our Motivation for this Book}

In light of the cost of textbooks and education in general, we undertook this project to create a free resource to be used broadly by students in a business context. We wanted to provide comprehensive coverage of the writing process, but keep our topics relevant to business education. We hope that this textbook provides equal value to both non- and native-English learners alike. Just like we acknowledge that students will continue to develop their writing skills, we expect this project to challenge and further our own skills as writers. We see this as a mutual journey and invite your comment for ways to improve the content.

John and Julie 


\section{The Writing Process}

Good writing means good editing. John Morris

After studying this chapter, you should be able to apply the basic concepts of our 3-part writing process (analyze, compose, and finish) to generate a business report that is concise, complete, and uses the essential vocabulary of business. You will read about tools and techniques we have found to be useful in the writing process. Finally, you will find a standard essay template as a generic format for most business reports.

\section{Writing a Report for Business}

As with most professions, business executives are busy, under pressure to take quick action, and often must make decisions with incomplete data. They value concise, well-written, and meaningful reports that succinctly analyze a problem, show insight using logical support, and provide clear recommendations.

Despite the need for frequent and reliable reports, these same executives will not read what they cannot understand. (By the way, the same goes for your instructors!) Therefore, clear writing and report quality are important elements of communication.

Writing clarity in a report demonstrates an understanding of the audience who will read it. Organization and structure of the report (thesis statement and topic sentences) are clear and specific. Writing mistakes are kept to a minimum so as not to 
distract from the readability of the report.

But, one size does not fit all either. Be aware there are regional differences between what an American executive expects and what one in Thailand expects. American culture, particularly American business culture, prioritizes data and information before everything else. In other parts of the world, in Latin and Asian countries for example, relationships and tradition receive top priority. Just like writing for business is different than writing for engineering, so is writing in the United States different from writing in Asia, Africa, Europe, or South America.

Report quality refers to satisfying the intention of the assignment as well as the specific deliverables requested. Sometimes, opportunities and threats are identified while completing assignments; these should not be ignored even though they may be out of scope. Sufficient information should be provided to enable a confident decision. Conclusions and recommendations should be fully supported with data and logic.

Because our experience comes primarily from working in business in the United States, the content of this book focuses on American business writing style. Similarly, when studying in the U.S., students are advised to write in an American business style; the following characteristics of American business writing will help.

Linear Thinking. Executives and managers prefer the linear, cause-and-effect style of thinking and writing found in American business. Leaders usually have more to do than they have time to do it and, therefore, demand direct, focused, and succinct reports. 
Writing in a linear format creates the kind of prose that business readers are likely to read.

Qualitative versus Quantitative Data. Unless you are a wellknown, world-leading expert on the subject, you'll probably need data from an expert source (such as the textbook, the case study, or other reading materials) to support your observations and claims. Use both quantitative data (numbers and statistics) and qualitative data (stories or anecdotes) to support your report.

The Rule of Adjectives. Business writing usually contains numbers and figures. Writing for business means using numbers to quantify your descriptions. Whenever you find yourself writing an adjective, ask yourself if using a number, percentage, or rate would be more descriptive. Words like more, less, better, worse, faster, slower, higher, and lower beg to be quantified.

Interrogate the Data. Describe the significance of what you are writing. It is not enough to simply list out data or to quote facts from a case study. You must also explain what it means and why it is relevant. Using the "5Ys" (asking why 5 times) is a useful practice that will help you get to the bottom of an issue. Think of yourself as an investigative reporter trying to scoop the big insight.

No Fluff. Executive summaries on a report allow harried leaders to know the relevance of what is contained in the report; they may never read the entire report. However, when they do read further, the report must be thorough, complete, and accurate or they will doubt your capability as an analyst. 


\section{Some Additional \\ Thoughts on Writing (not necessarily in business)}

Remember that your first draft is rarely your final draft. That means, never fall in love with your own writing! The writing process is one that involves multiple revisions, as detailed in the 3-part writing process section below. The more time

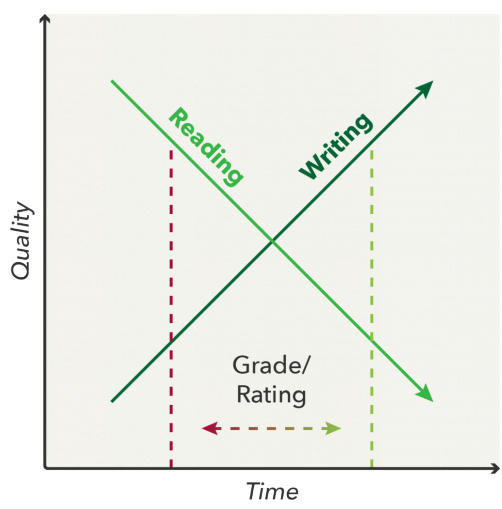

Figure 2.3 The impact of Time on Quality measured in terms of Writing and Reading effort and the resulting impact on Grade or Rating. you spend writing, the easier it will be for your reader to understand; in the academic world this translates into better scores, and in the work world, better job evaluations.

Finally, practice, practice, practice. The best way to learn the nuances of American business writing is through observation and practice-speaking, listening, reading, and writing in business English. You'll need to practice these skills extensively.

In line with how we opened this chapter and illustrated in Figure 2.3, we suggest the amount of time you spend on writing will directly impact the perceived quality of anyone reading it. That is, the longer you write, edit, and rewrite, the less time your manager or instructor will require to read and evaluate your report. In the workplace this translates into better performance ratings and in school, better grades. Do yourself a favor and spend the time to look good and get results.

To get a feel for how business writers write, consider making it a daily habit to read trade publications (like the Wall Street Journal). To see this style yourself, see the Resources for Getting Better and make a practice of reading what business executives are reading; look for these characteristics in how those publications are written. 


\section{The 3-part Writing Process}

The writing process can be loosely defined as the stages a writer goes through in order to complete a written task. The idea of teaching writing as a process, not a product, was coined by Donald M. Murray in the early 1970s, and revolutionized the way that writing was taught. Since then, the focus has come to be even more on the recursive process of writing, where each stage can be visited multiple times and can often lead back to the previous stage. We have categorized the process into three parts, with levels of headings and subheadings, but in reality the process is one of blurred steps, not distinct ones. Authors often move between stages in fits-and-starts, then return to earlier stages as an idea becomes better refined and clearer. And yet, writing is a deeply personal process, and one for which there is no correct formula. What we have constructed below is a guide, not a formula, for approaching the writing process, which should be tailored to fit your needs and style.

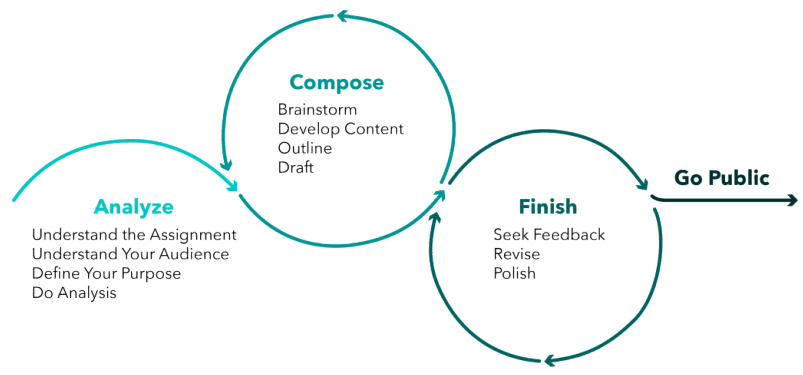

Figure 2.4

The 3-Part

Writing

Process 


\section{Analyze}

\section{Understand the Assignment.}

Understanding the assignment thoroughly is essential as it will be difficult to meet the assignment requirements and earn a high score without a clear understanding of what the assignment entails. In the future, without understanding what your boss has asked for it will be hard to impress them or your team with your analysis ability or even fulfill the requirements of the task.

When examining the assigned prompt (also known as the assignment description or requirements) ask:

What are the different parts of the prompt? Identify all separate elements that must be answered.

What keywords are present? Keywords may require definition or clarification from the accompanying reading or homework.

What verbs are used in the assignment? What does this assignment require me to do?

Don't rush this process, as it often takes time and reading the assignment description multiple times to fully comprehend the intricacies of the question or prompt. To improve your success at analysis, connect the question you are studying with what we have covered in class or in classes with related topics. What models or frameworks can you find to apply?

\section{Understand your Audience.}

It is essential to understand the audience and their unique needs, interests, or motivations. For example, if your audience is the CEO of a company, your content and style will be considerably different than if your audience is a co-worker. If your audience is someone very familiar with the project rather than someone unfamiliar with it, the amount of detail you go into for the report will differ. 
Therefore, it is necessary to assess what the audience's level of understanding of the topic is. If they are very familiar with a situation, less background information is needed; whereas if the audience is unfamiliar, you need to include more basic information and context. Obviously, you don't want to bore your audience by telling them something they already know, but you also don't want to assume they know more than they do and leave them lost or confused.

Always start by asking yourself "who is my audience?" In your business course assignments, audience will almost always be identified. Writing for your shareholders will entail different content and context than writing for your boss (or instructor). In a business school it is possible your instructor will have a preference for either academic or business style that coincides with their personal history. Academic writing will be more formal and use a third person perspective; business writing is less formal (but not conversational) and focuses on action or problem resolution. Those with academic backgrounds may expect you to write in an academic-style; those with a business background will likely prefer a business-style. If you are unsure which your instructor prefers, ask!

Determine what level of formality is needed. When writing to a "superior" (a higher level manager or your boss), a greater degree of formality is expected than when writing to a coworker. For example:

I'm wondering if it would be possible to extend the deadline of the analysis by one week.

I don't have the analysis done yet, so can I get a week extension?

The first example uses softer and less direct language with use 
of "wondering" and the conditional tense; this is appropriate for addressing a superior, whereas the second is more direct and would be suitable for communicating with a co-worker. Less direct language is generally wordier, which is something we recommend avoiding in business style communication. However, it is essential to address superiors with respect, and that often means being less direct. As a student, understanding this balance will come with time.

\section{Understand the Context for the Assignment.}

When reading the assignment prompt or the content of a case study or article to understand its meaning, pay attention to the situation that is being described. This context between the writer and the reader is critical in understanding the assignment and, most importantly, writing a compelling response.

A dictionary definition of context is "the parts of a discourse that surround a word or passage and can throw light on its meaning." Also, "the interrelated conditions in which something exists or occurs." Think of context as providing the backstory or the reason that a prompt is assigned in the first place. Context adds specificity to the assignment by relating it to something else happening in the organization or in your course. For example, if your textbook provides a lesson on Porter's Five Force Analysis of Market Structure and the course instructor has lectured on examples of understanding industries using that model, when the assignment asks for a market structure analysis the context dictates you should use Porter's model. Context clues are not always so obvious, but most instructors include them in some form.

Context needs to be understood fully in order to respond to the prompt in a meaningful way. To understand context, you may need to read the text multiple times. The first time through, read for a general understanding; what is the assignment about? That is, are you being asked to solve a problem, recommend a course of action, justify a decision, or something else? Identify the bigger picture of 
the case or problem. On subsequent readings, look for connections within the problem, case, or assignment to differentiate what elements to work on and in what order; how does the first part relate to the second part, and so on? The first part may be setting up a scenario and the second part asking you to decide between a variety of options. Also, identify connections between the assignment and the rest of the course. That is, create a deeper and more subtle understanding of the material relative to other topics that have been discussed in conjunction with the assignment. As illustrated in the previous paragraph, if your class has been talking about Porter's model, there is a high likelihood the assignment will be about the same thing. You may find it helpful to annotate-highlight and make notes-especially about the content that relates directly to the prompt.

When possible, look for opportunities to use specific models from your course or the broader business school curriculum and summarize your analysis in the context in which the prompt was assigned. Defer to your course for such tools, but see Chapter 4. Writing and Business Models for three examples of how this can be done using various business analytical tools.

\section{Define the Assignment Purpose.}

Look at the verbs used in the prompt; this will help you identify the assignment requirements. For example, common verbs may include: define, explain, persuade, and suggest (See Bloom's Taxonomy for a more thorough discussion of possible terms in your assignment.) Defining something is simpler than persuading someone to take action. Once you've examined the verbs used in the prompt, think of what you are trying to accomplish. If the assignment requires higher level thinking, like to persuade, think about what will be most persuasive to whomever you are persuading (i.e., your audience.)

Tip: Some students overthink the assignment purpose. This is different between the workplace and school. Your boss will rarely 
tell you to "generate a SWOT analysis", instead, they are more likely to ask you to "study the reasons for and against implementing a specific process improvement." It is up to you to identify whether a SWOT analysis or some other framework will fill the needs of the assignment. In school, however, your instructor typically creates assignments to support the course content currently being addressed. Start with this material and identify a business model in your current lessons to determine if it is actually the one being requested in the assignment. See Why Use a Model? for additional information.

\section{Reverse Outlining - An Alternative Approach to Understanding the Question Better}

The same way an outline can help you organize your thinking and kick-start your report, a reverse outline can help you more clearly understand the case you are analyzing. After reading the text once or twice, capture the topic of each paragraph in as few words as possible in the margin (if paper) or using a comment (if electronic) or in a separate document. Each paragraph description will be your first level of the reverse outline. Then read through each paragraph and capture the main ideas as sub-items in the outline.

Essentially, you are discovering (or recreating) the outline used by the author. This will help you see the flow and sequence of the author's thinking. Reverse outlining can help you find the most important elements of the case or reading and help you figure out how to compose a targeted report or case brief. 


\section{Consider the Format.}

At this stage, it isn't necessary to finalize your format, but consider some options and how each would impact your audience. Will you use full paragraphs, or would a bulleted list be more appropriate for the assignment? Business-style writing often takes advantage of bullets to eliminate extra words and highlight important points because the intent is often to create action. Bulleted lists do not need to be complete sentences, but should contain at least three separate, related items. These lists, however, may not fit with every assignment, or only work with a portion of an assignment.

Additionally, think about how the use of graphs, charts, tables, and related illustrations could draw the reader's attention. Figures can be a clearer way of displaying data, as compared to strictly text. If you do include them, figures should have a descriptive title and reference number. You should refer to the figure in your writing and place the figure in a convenient place near where it is referenced. Never use a figure in a business report without explaining its meaning or purpose. If you find that your figures are overwhelming your text, they can be moved to the appendix. See the section on Appendices for more information.

\section{Compose}

\section{Brainstorm - Develop Content.}

Writing in business can get complicated, as the ideas and concepts are often abstract. Making sense of the subject you are studying and the arguments you will be making takes multiple attempts. Certainly, this complexity is problematic to the creative process. It is difficult to even think about what to write when you are worried too much about how you are writing! Don't try to do both at the same time, instead, start coming up with ideas of how to answer 
the question by brainstorming in a style that works for you. Some examples could include making a list, mind map, drawing, or voice recording. Have fun. Get crazy. Be unrealistic. Remember, during this first part of brainstorming evaluating ideas is not the goal, generating lots of options is the goal.

It's essential to get all possible content down in whatever way you prefer. Devote plenty of time to this stage because these ideas will contain the seed of what will eventually become the heart of your report. When you can come up with no further ideas, determine the direction you want to go with your report based on you audience and purpose; then, limit ideas to only those that fit.

The final, and often overlooked step, is the organization of sources. For certain writing assignments you will use multiple sources and integrate them. Other assignments require the use of a single source and still others may not require any sources at all. If the assignment requires the use of multiple sources, in the brainstorming step you should clearly note where your information comes from, so you will be able to accurately cite sources in the drafts, final report, and reference list.

\section{Use Evidence.}

Addressing business problems can sometimes be sensitive work; after all, most business problems arise because of something someone did or neglected to do. Calling out errors and missed opportunities can create defensiveness and is unlikely to persuade. There is often a fine line between telling it like it is and crossing the line.

In business we sometimes have to tell our boss or our client news they won't want to hear and it may even make them angry. Recommendations and opinions are not readily received when seen as accusatory or pointing a guilty finger. To mitigate the damage bad news can bring and accelerate the time to get from an emotional 
reaction to a discussion of facts, learn to use a neutral tone and back-up your reports with concrete data, facts, and evidence.

In the academic world, instructors know their students have learned when they make a specific observation and support it with evidence from the textbook, case, or simulation. When answering questions or presenting recommendations, be specific and use data to support your observations and conclusions.

Keeping an objective tone-replacing subjective value judgements with observable facts and data-addresses both the business and the academic concerns. Stick to the facts; identify the trends; and use a historical context or universal standard as a comparison. It is much easier if you write with an objective tone from the beginning rather than create one at the end. Subtle word choice and tone can make all the difference in the quality of your report.

\section{Organize Content into an Outline.}

Consider how to divide your ideas into sections and subsections. Every assignment is different and requires unique organization. A 5-paragraph essay is considered a standard format, and may be appropriate for some assignments, while a different style is more fitting for other assignments. Understanding well what the assignment requires will lead to proper organization. See the essay template for an example.

Determine how many sections should be included and the contents of each. Outlines generally contain your big ideas at the top element (leftmost or outdented). The general rules of prose are suspended for an outline; it is okay to write in fragments and to ignore unessential words, phrases, and punctuation. Using as few words as possible, create a flow of the big ideas in logical order. Then add, combine, or remove items that don't fit as you work. Once the big ideas are in place, add more detail and progressively break each idea into its ever more granular components. Think of this as building the frame or skeleton of a building; this outline structure 
will be the thoughts that will hold everything up in your report. While there are no strict rules for outlining, there are guidelines which, if followed, will make your outline easier to turn into a draft during the next step of the process.

- Usually, outlines include a set of indented numbers and letters (e.g. in this order, I., A., 1., a., i.), a nested set of bullets, or a combination of the two. The style is less important than how they represent the flow of your thinking. Keep like items indented at the same level.

- Generally, keep the level of detail comparable throughout. That is, avoid using ten steps of indents in one area and none in another; this is an indication that you have strayed from the topic or that you have over- and under-developed elements in your thinking.

- All headings should be in the same grammatical form. If your first heading starts with a noun, the second heading should also start with a noun. For example:

I. Directions for employees

II. Recommendations for management

- Each heading should have one or more subheadings. If a heading will not have further details under it, it should be combined with another heading. For example:

I. Directions for employees

II. Recommendations for management 

A. restructure organization
B. examine salaries
C. look into HR practices

Above, the first heading (Directions for employees) is lacking detail, implying that there are no directions for employees. If this is the case, the heading should be deleted. Otherwise, this is an indication of an underdeveloped outline and detail should be added.

For reference, see the Purdue OWL website describing the process for Developing an Outline.

\section{Drafting Reports.}

Outlines are meant to be a starting place, so don't dwell too long on their creation. Once the frame is built and appears complete, begin transforming the outline into a report. Some points may transfer in whole to your report, others may need to be supplemented extensively to make them into complete and intelligible sentences. The length and style of your outline will usually help you decide when to keep ideas together in a paragraph and when to start a new one. If the previous steps of the writing process were done comprehensively, this step is a matter of converting the ideas from your outline to sentences and paragraphs. See theessay template for more details.

The key components the draft should include are:

An introduction paragraph, containing a thesis statement to give the reader a preview of what the report is about.

Body paragraphs, each containing a topic sentence followed by sentences that support and extend the topic sentence through the use of examples, data, and evidence. 
A conclusion paragraph which summarizes the main points of the report and leaves the reader with a sense of completion.

It's up to you how to create your draft and each student will be slightly different in their approach. Use the following suggestions to make the most of your initial draft.

Find a place to write that works well for you. You want to be in an environment that stimulates your creative juices and does not have a lot of distractions.

Decide whether you want to write by hand or on a computer. Though it seems like the easy and efficient choice to use a computer, some writers find that writing ideas out by hand is preferable to typing.

Consider writing body paragraphs first, and write the introduction and conclusion last. Often, the flow of your arguments will change as they become more concrete and polished; since they should be a summary of the entire report anyway, having the body first makes it easier to write the introduction and conclusion.

Write a thesis statement first and use it to guide the direction of your report. If your report heads in a different direction than you originally anticipated, you can always update your thesis statement so the thesis and the report are in sync.

Use the course's essential vocabulary. If you are stuck, you may be able to pull a term or concept from the assignment or associated reading material to help you move forward.

Use another creative way of getting your ideas out, such as recording them and later transcribing them onto paper. Don't let your need for perfection stop your creative thinking in the early stages of writing.

If your outline was done on a computer, copy and paste it into a document for congruity and turn the bullet points into full sentences. In most cases, nobody else will ever see your outline, so don't worry that you are reusing the same words-in fact, this will improve the continuity of the report.

Take breaks as necessary. If you feel stuck, take a break from 
writing. A walk, video game, or sport activity may help recharge your creativity.

Keep track of your sources. It's much more efficient to cite sources and compile your reference page as you go rather than waiting until the end.

Find the method that works best for you. Do you work best in shorter intervals of time? Or, is it better for you to set aside an extended amount of time? Whatever you do, don't wait until near the deadline to get started. If you like the pressure of a deadline, set the deadline artificially early so you have time to get done. If you meet the early deadline, you can relax knowing it is done ahead of time. Plus, your instructor will appreciate your timeliness.

However you choose to draft the report, the most important part of this step is that you capture and expand upon the content of your outline using sentences and paragraphs. After completing your draft, revisit your audience and the purpose of the assignment to check that what you wrote aligns with your purpose and meet the needs of your audience. Above all, realize your first draft should be revised multiple times before submission. The focus should be on getting started by getting something on paper. Don't aim for perfection, just get something down.

At this stage, revisit your outline and make sure everything you intended to include is included. Check for whether you are using essential vocabulary, have been complete, and are writing concisely. Look at your organization and determine whether you should use headings and subheadings throughout. For an example, take a look at this textbook, which is formatted in a business-style with clear headings. Also, consider options for titles at this time. Unless instructed otherwise, reports should include a descriptive title.

\section{Drafting Presentations.}

Your assignment may require a slide deck, report, and presentation, or a combination of the three. Though what we wrote in the analyze 
and compose sections aimed at writing a report, most of the analysis and composition recommendations apply to preparing a slide deck too. Again, starting with an outline is a good practice. But with slides, each level of the outline is likely to be a separate slide. The list of details underneath a major heading may actually be the content of its corresponding slide.

A common mistake is to create too many slides; expect each one will take about 1-2 minutes to adequately cover during the presentation. If you have 10-minutes to present, you will want 5-10 slides-probably erring on the lower end of that range. Having the right number of slides is as much an art as science, however. If a slide has a single point of information, it might be appropriately combined with the one before or after. But, if that single point is the most important one in your presentation and you will spend most of your time on it, more likely it should be left on its own and made the focal point of the presentation.

Finally, consider the content of each slide. Your driving concern should be to display the information in a way that is clear for your audience. Avoid writing complete sentences. Instead, identify a keyword that represents the point and list just that word or phrase. Complete sentences may cause your audience to read ahead or you to read to them; some may consider this insulting or a waste of time. Always consider your audience and the purpose of the presentation. If you are presenting to the class and your instructor about something from your textbook, it is safe to assume they have already read the source material and it is only necessary to repeat items that are absolutely essential to the prompt. If you are presenting to the general public, you'll need to provide background and context. But, don't get so hung up on context that you run out of time to address the purpose of the presentation. A good general rule is, if it will add clarity leave it in, otherwise, remove it from the slides or presentation... whatever the "it" is!

See Tips for Creating Effective Slides later in the textbook for more information. 


\section{Finish}

Finishing the report is the final and often most overlooked step. Once you've reached this point, it's easy to think you're done. Yet, at this stage, there is still more to do to see your report through to its completion. As with the previous steps, this step is essential. Above all, be sure you have answered the question fully but that you omit everything that is unnecessary regardless of how interesting it is. Reread your response and ask, does it answer the question you were asked?

\section{Seek Feedback.}

Even the best educated among us can be better writers. The writing muscle is one that gets stronger and more capable as it gets exercised. But, we often do not recognize mistakes in our own writing. As college educated learners, we should all be continuously seeking ways to improve our writing. Seeking the help of others we trust is one sure-fire way of getting better.

In this stage, you should not be afraid to make significant changes to your report based on others' suggestions. By this stage in the writing process, you will have spent a considerable amount of time on your work and may feel attached to it. However, do not become so attached that you are unwilling to take suggestions. Often, others have a keen eye for what you have not recognized yourself, as they are seeing your work from a fresh viewpoint. Be open to suggestions from trusted people, even if you do not completely agree with them.

Before going to others, go through the report one last time yourself. Read your writing aloud and listen for what sounds awkward. Do you stumble when reading a specific passage? If so, a reader seeing your report for the first or second time is likely to stumble too. Listen for redundancies, missing steps, and ambiguous passages.

Then, use the resources available to you. This could be a trusted 
friend or classmate. Or, use the resources available through the university's writing center. Most universities have writing centers, where students can get writing help from student employees or staff who are trained in giving feedback on writing. It is our experience that making appointments in advance so you can meet with the same writing consultant each time is a good practice. The steps of both revising and polishing are detailed below; use the resources available to you in both steps.

\section{Revise - Focus on Global Issues.}

Addressing global issues refers to improving the content and organization of your report. This can include adding, deleting expanding or clarifying ideas and the rearranging of paragraphs or ideas within them. For presentations, this might mean changing the order of your slides or splitting or combining slides. These major issues need to be addressed first as they are fundamental to fulfilling the assignment requirements. Addressing small issues (obsessing over spelling, grammar, and punctuation) at this stage is unnecessary until major issues are addressed. Instead, your focus should remain on making substantial content-related changes at this stage.

First, consider the structure of your report and arrange it for clarity. Look critically at how the parts fit together. Rearrange the parts as necessary in effort to have a clearer organization and tie the parts together. Refer back to your outline and consider whether the structure of your report follows the same organization as you intended in the outline. Review your introduction and conclusion paragraphs to ensure all appropriate information is included. It's easy to stray from what you intended to write when writing freely or if you felt you were on a roll. Now is the time to look for the places where you may have deviated from your original topic.

Looking at the report as a whole, consider whether you may have strayed from the assignment requirements? Does every paragraph 
add value to the report and seek to address the assignment requirements? Are the paragraphs arranged logically and in a way that is easy for the reader to follow? Are there gaps in logic that should be explained?

Looking at each paragraph, consider whether each paragraph has a central theme with a topic sentence that states that theme. Does each paragraph contain details, data or evidence to expand upon the idea presented in the topic sentence? Are there details, data or evidence which do not support the central theme of the paragraph?

Looking at each sentence, consider whether the sentences flow well. Are all the transitions you used necessary? Have you over- or under-used transition words? Are there ways to connect your ideas using pronoun referencing rather than transitions?

Finally, decide if anything is better suited to the appendix. If you have an elegantly crafted and detailed calculation around a specific business model that you created early, but your report has since taken a turn in a different direction, that section probably doesn't belong in the main portion of your report. However, if it remains well-done and provides at least some tangential value, consider whether it belongs in an appendix. See the section on Appendices for more information.

You can use the following checklist as you go through the revise step:

- Have I answered the question in the prompt or have I strayed away from it to something that I preferred to write about?

- Is everything I've included relevant to the report's topic? Are any parts irrelevant and able to be removed?

- Do I have a clear thesis statement at the end of the introduction paragraph and clear topic sentences at the beginning of each paragraph?

- Have I used adequate support (examples, data) to support my opinion?

- Have I used appropriate evidence from the case to support my opinion? 
- Does my organization allow my argument to be easily understood or would a different type of organization be clearer?

- If there are multiple parts to the prompt, is each part adequately covered or is one part addressed more thoroughly and others lacking?

- Are transitions used to guide the reader through my report? Have I limited transitions as to not overuse them?

- Have I used proper formatting?

\section{Polish - Edit Sentence-Level Issues.}

Polishing refers to making the report correct in terms of grammar, word choice, tone, pronoun use, spelling, punctuation, and other writing mechanical issues like writing tight and keeping it objective. Writing tight means removing unnecessary words and ideas, those that do not add direct value to your report as required by the assignment prompt. Later, in a business context, it will mean the same thing but it will show you as someone who is eager to solve problems instead of someone who is eager to show off what you know.

In general, delete the unnecessary. Look for repetition; avoid repeating ideas and words. Experiment with synonyms but have a keen awareness of the words you're using as it is essential you don't stray from the topic. When considering word choice, prioritize clarity over variety.

For example, if you look up the word "happy" in the dictionary, you will find synonyms such as "cheerful" and "merry". However, if you are reporting data from a survey about what brings people happiness in life, the 
use of either of those synonyms would be inappropriate since they imply temporary happiness, rather than sustained happiness.

By prioritizing clarity over variety, your intended meaning will better come through.

\section{Go public.}

The final step is to submit your assignment. This could mean submitting the report through your university's learning management system or giving the presentation itself. Once you've done this, you should feel a sense of accomplishment and look forward to your instructor's comments on your work, so you can keep learning in this continual process of becoming a better writer. 


\section{A Standard Essay Template}

Below is a template that can be used for a standard essay. The keyword here is "standard", meaning that while this is a place to start in terms of organizing a paper, it should be modified to fit particular assignments and reach the intended audience. Every writing assignment should contain an introduction and conclusion paragraph, however, the exact number, organization, and content of body paragraphs will differ based on the assignment.

Introduction - The introduction paragraph should provide a brief restatement of the topic. When writing this, consider your audience and what their level of knowledge about the topic is. While it is necessary to be general, telling your audience what they already know can come across as condescending (at worst) or unnecessarily wordy (at best). See the example.

Writing the introduction to a case brief about the Kellogg's company, you can assume your reader already knows that Kellogg's is in the cereal industry. One 
option is to restate the assignment prompt such that it sets context for the content that follows and appears to be resolved by your thesis statement. In this example, the prompt was "If Kellogg's were to expand its business, what single recommendation would you make? Defend your recommendation."

Poor: Kellogg's, a producer of breakfast cereal, is in the cereal industry.

Better: Kellogg's is facing an existential quandary, whether it should expand its existing lines of product or expand into healthier opportunities.

Following the general introduction, you should have a thesis statement. Your thesis statement should tell your reader the purpose of your essay and give your reader a preview of the content and organization of your essay. It should contain the topic, claims and major points. This video provides further explanation.

Body Paragraphs - The number of body paragraphs used will be dictated by the assignment requirements, as will the amount of support, evidence and development. In general, start each body paragraph with a topic sentence keeping in mind the knowledge of your audience, then provide evidence in a natural progression to support that topic and finish the paragraph with analysis of the evidence by answering the question, "So what?" That is, tell the reader why the evidence you provided should be important to them. In American schools, these are called TEA paragraphs. This video provides further explanation.

Conclusion - essentially the inverse of how you opened your report, the conclusion is a single paragraph that starts narrow and broadens into the final conclusion. The purpose of the conclusion 
is to tie in what you have previously written in the body paragraph and give a sense of closure to the reader. This paragraph should contain a restatement of the thesis, emphasize the main point(s) of the report and answer the question "so what?". The answer to this question could include the wider implication of your findings or opinion, or how it relates to a broader concept, essentially broadening the report to conclude. This video provides further explanation.

\section{Introduction:}

Introduction sentence

Thesis statement

\section{Body Paragraph 1:}

Topic sentence

Supporting detail (plus evidence and/or development)

Supporting detail (plus evidence and/or development)

\section{Body Paragraph 2:}

Topic sentence

Supporting detail (plus evidence and/or development)

Supporting detail (plus evidence and/or development)

\section{Body Paragraph 3:}

Topic sentence

Supporting detail (plus evidence and/or development)

Supporting detail (plus evidence and/or development)

\section{Conclusion:}

Restatement of thesis + the big so what? 


\section{Writing Essentials}

Never fall in love with your own writing. John Morris

This chapter is a close companion to the 3-part Writing Process introduced in Chapter 2. In fact, it was born of our desire to keep that process as tight as possible without compromising some of the specialized tasks students often find relevant to their assignments. Our intention was to keep Chapter 2 consistent with a generic process for business school that will fit the majority of assignments. To enable this focus on the overall process, we created this chapter of writing essentials to capture common one off items. We consider these as one off because 1) they support the basic writing process of analyze, compose, and finish; 2) all courses have unique skill requirements so the instructor may have varying interests in how you do these things; and 3) doing these things will not harm any student's grade despite the individual expectations or tastes of the instructor.

\section{Formatting a Business Report}

The primary reason for writing is communication and this does not vary between disciplines. However, there are differences between academic and business writing styles. In business writing, we tend to be informal and use a perspective that matches the circumstances. In academic writing, the tone is more formal and we are biased toward a distant, third-person perspective as evidenced by the choice of pronouns and a clinical tone. Both academic and business writers emphasize facts, but business writers give opinions too. Academics use long sentences, but business readers see such writing as stilted and cumbersome. But note, while business writing 
is less formal than academic writing, it is not conversational. Avoid using slang! 
Figure 3.1 Academic and Business Writing Compared

\begin{tabular}{|c|c|c|}
\hline Characteristic & $\begin{array}{l}\text { Academic } \\
\text { Writing }\end{array}$ & Business Writing \\
\hline Purpose & $\begin{array}{l}\text { Learning and } \\
\text { demonstration } \\
\text { of mastery. }\end{array}$ & $\begin{array}{l}\text { Writing actionable items, calls to } \\
\text { action, and getting things done. }\end{array}$ \\
\hline Appearance & $\begin{array}{l}\text { As identified by } \\
\text { the instructor, } \\
\text { typically } 1^{\prime \prime} \\
\text { paper margins, } \\
\text { a title, and page } \\
\text { numbers using } \\
\text { paragraph } \\
\text { indents, } \\
\text { double-space, } \\
\text { and } \\
\text { twelve-point } \\
\text { Times New } \\
\text { Roman font. } \\
\text { Visually, it is } \\
\text { uniform and } \\
\text { boxy. }\end{array}$ & $\begin{array}{l}\text { Typically not specified, dictated by } \\
\text { subject matter and the firm's } \\
\text { tradition. Single spacing (or maybe } \\
\text { 1.15) is common with frequent use } \\
\text { of white space and page numbers. } \\
\text { Uses titles, headings, and } \\
\text { subheadings along with bulleted } \\
\text { and numbered lists, graphs, } \\
\text { charts, logos, and pictures. Fonts } \\
\text { vary, but are generally friendly but } \\
\text { not cartoonish. } \\
\text { The effect is visually attractive and } \\
\text { pleasing yet the document can be } \\
\text { quickly scanned, or read more } \\
\text { slowly for details. }\end{array}$ \\
\hline Audience & $\begin{array}{l}\text { Your teacher or } \\
\text { instructor. }\end{array}$ & $\begin{array}{l}\text { Driven by circumstances; depends } \\
\text { on the interests and needs of the } \\
\text { specific stakeholders. }\end{array}$ \\
\hline $\begin{array}{l}\text { Document } \\
\text { Life }\end{array}$ & $\begin{array}{l}\text { Since an essay } \\
\text { or exam is the } \\
\text { typical product, } \\
\text { its useful life is } \\
\text { usually very } \\
\text { short-lived. } \\
\text { Typically, kept } \\
\text { for reference } \\
\text { until the end of } \\
\text { the term or } \\
\text { some } \\
\text { institutionally } \\
\text { mandated } \\
\text { period. }\end{array}$ & $\begin{array}{l}\text { The document is generally just a } \\
\text { starting point and can transition } \\
\text { into other forms of } \\
\text { communication (written } \\
\text { documents become oral } \\
\text { presentations or formal } \\
\text { presentations become informal } \\
\text { meetings). Parts of documents } \\
\text { may take a life of their own, being } \\
\text { reused multiple times in different } \\
\text { contexts by the same and different } \\
\text { authors. Some documents may be } \\
\text { stored in a firm's knowledge } \\
\text { management repository for reuse } \\
\text { or for regulatory or legal reasons. }\end{array}$ \\
\hline
\end{tabular}




\begin{tabular}{|l|l|l|}
\hline Citations & $\begin{array}{l}\text { Direct quotes } \\
\text { and } \\
\text { paraphrasing } \\
\text { from outside } \\
\text { sources must be } \\
\text { cited in } \\
\text { predetermined } \\
\text { academic } \\
\text { conventions like } \\
\text { Chicago, MLA, } \\
\text { and APA. }\end{array}$ & $\begin{array}{l}\text { Once created, content of reports } \\
\text { becomes the firm's property and } \\
\text { paraphrased, quoted, and } \\
\text { boilerplated text is not cited. If } \\
\text { outside sources are used, citation } \\
\text { varies according to the needs of } \\
\text { the audience or client. }\end{array}$ \\
\hline Tone & $\begin{array}{l}\text { Authoritative, } \\
\text { yet inquisitive } \\
\text { to show the } \\
\text { author has } \\
\text { knowledge } \\
\text { about their } \\
\text { topic and thesis, } \\
\text { but is open to } \\
\text { new learning. }\end{array}$ & $\begin{array}{l}\text { Driven by circumstances; depends } \\
\text { on the interests and needs of the } \\
\text { specific stakeholders. May be } \\
\text { friendly, authoritative, persuasive, } \\
\text { or even argumentative. }\end{array}$ \\
\hline $\begin{array}{l}\text { Usually passive, } \\
\text { especially in } \\
\text { science writing. } \\
\text { Passive voice } \\
\text { prioritizes the } \\
\text { experience of } \\
\text { an action over } \\
\text { the } \\
\text { performance of } \\
\text { that action. }\end{array}$ & $\begin{array}{l}\text { Always uses an active voice, one in } \\
\text { which the subject performs the } \\
\text { action stated by the verb. For } \\
\text { example, The CEO (subject) } \\
\text { ordered (verb) her team to get in } \\
\text { line or get out." Active voice tends } \\
\text { to use fewer words, be more } \\
\text { direct, and easier to understand. }\end{array}$ \\
\hline
\end{tabular}

\section{Understanding Assignment Requirements}

Bloom's taxonomy is a framework with which to classify skills; it is based on the 1950s research of Benjamin Bloom and is sometimes referred to as levels of thinking. Because it's useful in calibrating difficulty, many instructors employ Bloom's taxonomy to write learning objectives and assignments. The lower level (easier) skills, such as remembering, set the stage for higher level (difficult) skills, such as analyzing or evaluating. In a given course, and indeed across 
the curriculum as a whole, students are asked to demonstrate lower level skills first and to progress to higher level thinking; the starting point is often referred to as foundational while the endpoint can be thought of as mastery. Sometimes mastery is called Critical Thinking. For the purposes of this guide, the levels will be explained as they relate to the ways they might be used in assignment descriptions or prompts.

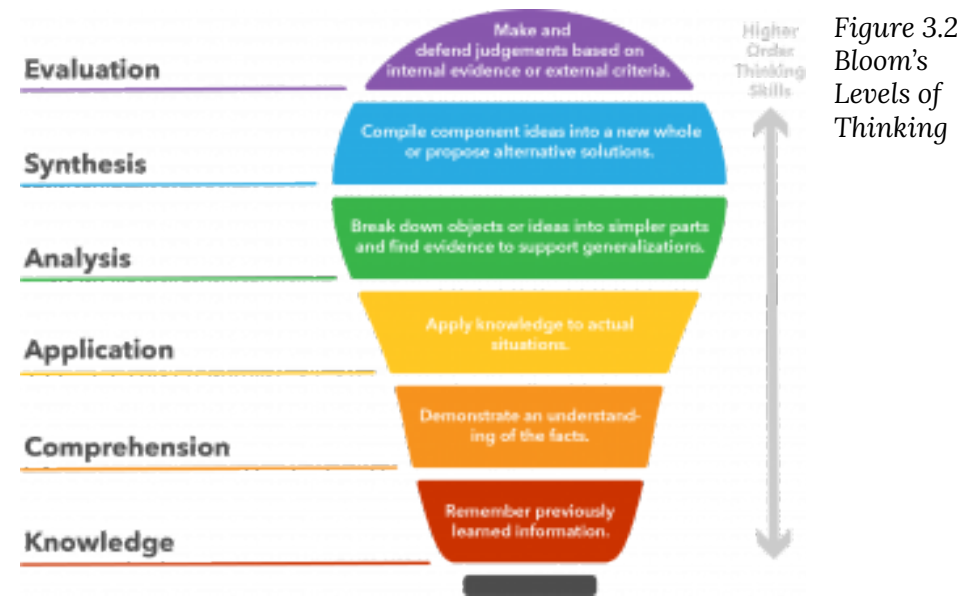

As you read through each of the level descriptions below, recognize that the verbs your instructor chooses in an assignment prompt identify the levels of thinking they expect from you as a student. The common verbs we listed are representative, not exhaustive; your specific discipline may even have its own vocabulary around each of these levels of thinking.

Regardless of the discipline, the foundational level always starts with knowledge specific to the subject and then progresses to comprehension, application, analysis, and synthesis and culminates in mastery as demonstrated through evaluation. Just like an artist must first learn about the variety of implements for placing paint on canvas (knowledge) before they actually dip their brush into a jar of paint, students of business must first understand the vocabulary 
they will need before trying to understand a theory or model. Likewise, the same student needs to comprehend the business theory before they can apply it to a case. Learning progresses along these levels of learning.

The tool that Bloom gave to teachers through his taxonomy makes describing this progression easier. And this progression works equally well whether moving through a subject or a discipline. That's why BA 101 comes before BA 211. As you read assignments in your various courses, pay attention to the descriptors; they will help you understand how complex your responses should be.

Which of the levels an assignment falls into is not always clear or obvious, and it may not be possible to merely use the assignment's verb choices to determine its category. Higher level assignments in particular build on and often use the terms from lower levels of Bloom's Taxonomy. So it may be helpful to fully understand each verb of the assignment and what level of thinking it demands, using Bloom's Taxonomy as a guide. 


\section{Knowledge Level}

Common verbs: arrange, define, describe, identify, label, list, name, order, recall, select, state

For example:

Identify the four parts of a SWOT analysis.

Name the three stages of the value chain.

These prompts are simple; they are asking you only to state the parts of something, either the parts of a SWOT analysis or the stages of the value chain. Therefore, these two examples do not require you to go beyond stating; that is, once you have replied "strength, weakness, opportunity, and threat" to the first prompt, you are done. Obviously, this type of question is very basic. If used at the beginning of the term or in a foundational course for a degree program, it may be a multiple choice or short answer type question. If it comes later in the term or curriculum, it is usually paired with a higher level question.

\section{Comprehension Level}

Common verbs: comprehend, classify, define, discuss, explain, summarize, paraphrase, restate

For example: 
Explain the four parts of a SWOT analysis.

Summarize what happens at each stage of the value chain.

Note in the previous level, knowledge, you only had to identify or name the parts of SWOT or a value chain. Now at a comprehension level, you would be required to go beyond just stating the terms to explain what role each part plays. Comprehension involves a more in-depth knowledge of the process or model. So, if you stopped at "strength, weakness, opportunity, and threat" when responding to the prompt above, you would receive no or only partial credit for your answer. In other words, comprehending a model is a higherlevel of thinking than just knowing what the parts are called. 


\section{Application Level}

Common verbs: apply, chose, construct, compute, determine, develop, extend, predict, report, use

For example:

Use SWOT to describe the future prospects of Company X.

Construct a drawing of Company X's major value chain activities.

With application, you are expected to demonstrate a higher level of thinking than comprehension. You must use what you know and understand about SWOT analysis or value chain within the context of a new situation. To do this, you also need to apply what you know about Company X's business to the specific model. At the application level, you must still know and comprehend the SWOT model, but you must also apply its rules and principles to describe Company X's specific future prospects.

Clearly, as you progress to this third level of thinking, if you had not yet mastered either of the previous ones, it will show up in how you describe those particular prospects. In other words, if you thought that "S" represented "strategies" instead of strengths, your answer will appear nonsensical to anyone who has mastered these three levels of thinking relative to SWOT analysis.

\section{Analysis Level}

Common verbs: analyze, break down, compose, contrast, differentiate, distinguish, examine 
For example:

Distinguish between the unique strengths of Company X and Company Y.

Analyze Company X's value chain to identify its primary vulnerabilities.

At the analysis level, you are able to split up a subject into component parts in order to examine how they relate to each other. As with the earlier levels, you are still expected to have mastered less complex thinking before being challenged to analyze; now you not only understand the context for using a model, you also understand the content being studied and how it is organized, making this a more complex and nuanced task than application.

Distinguishing between the strengths of two independent entities-Company $\mathrm{X}$ and Company $\mathrm{Y}$-requires the student to use the appropriate language (knowledge), correctly (comprehension), within the context of each's strengths (application), and compare the relationship correctly. So, if Company $\mathrm{X}$ is known for its market power and brand and Company $\mathrm{Y}$ is known for its market power and scale of operations, the student will need to explain what these distinctions mean to each company; that is, describe the implications of brand to market power in contrast to scale of operations to market power.

\section{Synthesis Level}

Common verbs: adapt, arrange, compare, categorize, formulate, integrate, organize, propose, write

For example: 
Compare the likelihood of success of Company X if they spend money to improve their existing software (strength) versus if they streamline their production process (weakness).

Propose a revision to Company X's supply chain organization.

Going beyond a break down exercise (analysis), these prompts are asking the student to generate a complete argument by combining their understanding of each of the parts. To demonstrate a mastery at the synthesis level, the student is expected to be able put the parts of a thing back together in order to create a new whole that is different than what existed before. Such comparisons or proposals rely on analysis using a properly applied framework, but the student is expected to be much more complete. For example, the instructor may expect a formal report or persuasive proposal.

\section{Evaluation Level}

Common verbs: appraise, assess, conclude, criticize, defend, justify, critique, persuade, predict

For example:

On which part of the SWOT analysis should Company $X$ focus in order to ensure its future success? Defend your choice. 
Describe the value chain activities for Company $\mathrm{X}$ and Company Y? Conclude which company operates more efficiently and suggest improvements for each.

In the first prompt, the student must first understand all parts of the SWOT analysis in order to determine which is most important. Then they apply what they know about both Company X and Company $\mathrm{Y}$ and the market in which they both operate. Not only will the student need in-depth knowledge about the models, companies and markets, but they must evaluate each in order to derive a conclusion. This involves extensive research, analysis and finally integration before arriving at a conclusion. But, the student is not yet done because they must also defend their choice. This involves appraising all of the previously mentioned information and prioritizing that information based on its merits, in order to create a persuasive defense! 


\section{Thesis statements}

A thesis statement is a sentence that states the main idea of a report. Its purpose is to give direction to the report and let readers know its content. See the example, Thesis Option \#1. Note how the thesis statement clearly responds to the prompt, but without going into detail; the specific information about how the company will ensure its future success will be addressed in the body paragraphs of the report.

A thesis statement can also contain a supporting point, if that point will be the central theme of the report. See the example, Thesis Option \#2. Either thesis statement works and which one you choose depends on how you want to approach the prompt.

All reports should include a thesis statement, but the length and content will be determined by both the assignment and author's preference. When crafting a thesis statement, consider your response to the prompt, your personal opinion on the topic, or what you believe is the strongest argument. The thesis should be drafted at the beginning of the writing process to serve as your guide and then revisited (and probably rewritten) during the polishing phase to ensure it is still in alignment with the theme of the report.

Prompt: On which part of the SWOT analysis should Company $\mathrm{X}$ focus in order to ensure its future success? Defend your choice.

Thesis Option \#1: To meet their long-term objectives, Company X should pay the most attention to their strengths, specifically the development of AppX.

Thesis Option \#2: To meet their long-term objectives, Company X should focus on their strengths, 
specifically the development of AppX technology, because they are currently the only company that uses this highly innovative technology.

\section{Keeping writing honest and avoiding plagiarism}

\section{Plagiarism and How to Prevent it}

Merriam Webster's dictionary defines plagiarism as "to steal and pass off (the ideas or words of another) as one's own or use (another's production) without crediting the source". Examples of this could include copying someone else's work and calling it your own or improperly citing portions of another's work. Whether intentional or unintentional, plagiarism is a serious offense and will be dealt with in a serious manner by university officials. However, students' desire to maintain honesty in writing should be driven not by the fear of consequences associated with plagiarism, but rather the knowledge that they have acted in an ethical manner, and their writing reflects that.

Maintaining honesty in writing requires continuous commitment from the writer. The responsibility for avoiding both intentional and accidental plagiarism falls completely on the writer and anytime a writer attaches their name to an assignment, it must be completely their own. Identifying the common causes of plagiarism will help you understand the best ways to prevent it. 


\section{Common Causes}

There are a few common causes for plagiarism.

Inexperience. Students do not know how to properly cite works. Citing properly according to a style guide requires a lot of attention to detail. There are many online resources that can help with this and you will get better with practice.

Misunderstanding. Students may not understand the necessity of citations. Especially students from cultures where borrowing someone's work is considered as giving them honor, rather than stealing as it is in American culture, the concept of citing work may be unfamiliar. Knowing the norms of the culture and system you are living and working in and the standards that universities hold students to is key to preventing plagiarism.

Carelessness. Students are unsure of how to approach the assignment or lack confidence in their own work. However, learning is a process, and by copying someone else's work rather than engaging in the process of learning, students are only selling themselves short. When unsure about how to complete an assignment, it's best to ask for help, a process which you will learn from.

Procrastination. Poor time management and procrastination can also lead to plagiarism. When students feel they are unable to complete an assignment on time, they may feel their only choice is to plagiarize. Staying on top of deadlines and being realistic about the amount of time assignments require can help with this.

Oversight. When participating in group work, students rely on others to correctly cite. With group assignments, all members of the group are responsible for the content, so if there is an improper or missing citation, each member will face the consequences. It's a good idea for all members on a group assignment to be responsible for proofing the document and looking for potential problems. 


\section{What and How to Cite}

Citing means giving proper credit to the creator of the intellectual property that you are using in your research. Citations generally require the author's last name, date, title, source and link to the source, though these items and their sequence vary among the citation styles.

There are three main styles of citations. The style of citation is just that-it's the way a citation is displayed both in the text and in the reference list. The style of citation used depends on both the academic discipline and professor's preference. Some professors don't mind if students use whatever citation style they are comfortable with, while others are more particular and require students to cite in one particular style.

Regardless of citation style, sources need to be cited in two ways.

In-text citations. These citations appear in the text, after the information that you are referencing and are in either parenthetical or footnote form, depending on which style of citation you are using. Both paraphrased and directly quoted information need to be cited (though in different ways) and a general rule is that a phrase of more than 4-5 consecutive words taken from any source needs to be cited. The way to cite directly quoted and paraphrased material depends on the citation style. No matter which citation style you're using, the author's last name needs to be shown in-text or in the footnote, and the full citation must appear in the reference list.

Reference list (also called Works Cited). This is a list of sources which needs to be included at the end of your report. The list must contain all the sources you used in your report and will either be in alphabetical order or the order in which they appear in your report. Chicago, APA, and MLA styles have very particular rules about what information needs to be included from each source and how it is displayed, so consult the manual for details on how to compile a reference list.

As mentioned, citing properly in a given style is best done using a 
manual of that particular style. Manuals are widely available online. One comprehensive and well-known website with these manuals is Purdue OWL, the online writing lab run by Purdue University. Chicago, APA, and MLA manuals of style can be found there. This video and this Citations 101 website will provide further explanation. By the way, although you might like to include an impressively long list at the end of your report, avoid the temptation of including sources that you did not cite; that is a bibliography. In a bibliography, you list all material you read or reviewed when preparing your report. Unless specifically requested, most instructors are not interested in a bibliography.

Because citation style is generally determined by the course instructor, it's best to follow their instructions. Although we are using a Chicago style, this textbook specifically avoids promoting one style of citation over another. If your instructor doesn't specify a style, you should be sure to ask.

\section{Writing for Persuasion}

Persuasion is selling and business is all about selling. Whether selling your idea to investors, persuading a client to buy your proposal, or persuading your boss to take your suggestions, there are elements of persuasion in nearly all aspects of business. Indeed, even in school, there is an element of persuasion in getting the scores on assignments you deserve and the grades you desire.

There are several elements to persuasion that are important to keep in mind which were addressed generically in the 3-part Writing Process. But let's put those in the context of writing to persuade. First, you need to understand your audience and what they want. The elements in the Analyze portion of the 3-part Writing Process address this task from several angles, but importantly, they help you put your words into words that your audience will absorb.

50 | Writing Essentials 
Once you know the objective of your writing (referred to in the 3-part Writing Process as "assignment purpose") you must dive into the data. Mark Twain famously popularized the saying "There are three kinds of lies: lies, damned lies, and statistics." The headlines in the popular press are full of business executives going to jail over some kind of deception or act of omission. Your boss (and your professor) do not want you to make up facts in order to create a persuasive argument; this is the literary equivalent to putting lipstick on a pig, because no matter how nice you try to make the pig look, it is still a pig!

Digging into the data means getting answers that will support your stance. As the Twain quote implies, however, sometimes this means looking at the data from a variety of perspectives. If you come to a conclusion that is obviously questionable, be prepared to explain your assumptions. Knowing why a stance is not convincing is often as important as having a strong set of arguments in support (see the next section on counterarguments). But, let's stick with crafting your position persuasively for just a bit longer.

Using data is powerful in defending a position. How many times have you debated with your buddies over the merits of some particular figure or event only to have someone pull out their phone and ask Google for an answer? If you are arguing which city is bigger, census data provides a sufficient comparison and debate concluded. Likewise, comparing the wisdom of one approach over another relative to a marketing problem can be furthered or hindered through the application of data.

Data, when used in conjunction with an appropriate business model, is even more persuasive. When professionals look at problems, they are generally assessing an appropriate framework to understand what is happening, which will then yield a path forward. When an investor is asked about a stock, they examine its historical records, its current $10-\mathrm{K}$, and may determine its price-to-earnings ratio before providing a recommendation. When an attorney examines the liability for a consumer product, they will examine the evidence, look at previous case law, and apply a standard of probable 
cause. Both the financial ratios and legal precedents are business models that provide a framework for a decision. As a student of business, it behooves you to act in an equally professional manner by looking for an appropriate business model to frame your arguments.

When making your case, ask yourself if you have an effective position that is supported by the facts; you are not ready to transition from analysis to composition until you do. Then look for a good "hook" to grab the attention of your reader and encapsulate your position by speaking directly to a need of your audience. Use effective editing to get all unnecessary words out of the way. Look for graphics or figures that will support your position. And, look at the most convincing argument in opposition to your position and decide how you can most convincingly refute it.

\section{Writing a Counterargument}

In order to be persuasive in writing (and in presentations), counter argumentation can be used. A well crafted counterargument takes place in two steps and will enhance the persuasive ability of a report or presentation.

A counterargument is a statement that goes against your claim, which is then followed by a statement that proves your claim is still logical or sound. When trying to persuade your audience, either in written form or through a presentation, you first make a claim and support it with reasoning, evidence, and data. Then you adopt a skeptical tone from the perspective of those who might resist your argument (first step). You point out a convincing conclusion or a key assumption that goes contrary to your initial stance. Think of this as a turn against your own argument. Finally, you turn back to your original argument (second step) using a "but", "yet", "however", or something similar to highlight the logic or evidence that outweighs the possible opposition. You show that you have considered the 
strongest counterargument and that your argument prevails. A more detailed description of how to construct a counter argument is given in the next section.

Always consider your audience, and the objections they may have to your opinion or proposal. Brainstorm why your audience would disagree with you, and the support they would use to disagree with you. The turn against should contain: drawbacks to your claim, an alternative conclusion drawn from the same data, or a different conclusion that makes sense within the context of your argument. It is key to both present the argument against your thesis and elaborate on why others would support that argument. The elaboration does not have to be lengthy (1-2 sentences is fine), but does need to succinctly and clearly support the opposing view.

Including a counterargument in writing is a method of persuasion with two primary benefits. First, it shows that you have considered and are willing to acknowledge multiple points of view before settling on one. In business, there is rarely one clear-cut solution to a problem and all viable options need to be carefully weighed. Showing that you, as a writer, have approached the issue from two or more perspectives enhances the credibility of your final opinion. Secondly, it also allows you to address possible objections to your opinion and refute them (prove them wrong), which shows readers who may object initially that there is a better option.

Skillfully writing a counter argument requires higher level thinking, the ability to understand multiple perspectives, and good planning. But, be careful using counterarguments. If your logic is trite or your approach obviously feeble, you will do more harm than good to your report.

Counterarguments will not enhance all reports, so consider whether the assignment calls for one. If the purpose of the assignment is anything other than persuasion, a counterargument is not appropriate. For instance, in the previous section on levels of thinking, you learned that responding to the prompt "Explain the four parts of a SWOT analysis" is a low level (comprehension) in Bloom's Taxonomy. When answering this question, it's not useful 
to include a counterargument because there is no argument in the first place. However, in the question "On which part of the SWOT analysis should Company X focus in order to ensure its future success? Defend your choice" you are required to give an opinion and it is your goal to persuade your audience to agree. By presenting your opinion, proposing a counterargument (in this case, the suggestion that another element of SWOT is more important), and then refuting that opposition, your argument is made stronger. 


\section{Constructing the Counterargument}

The counterargument is generally positioned in one of two parts of the paper, either immediately after the introduction paragraph or right before the conclusion paragraph. The counterargument should be contained in one complete paragraph, not interspersed throughout multiple paragraphs.

Your counterargument will make up the first part of its own paragraph. Start your counterargument paragraph with terms that allow your reader to know you are presenting the opposing point. Possible phrases to use are:

Some may argue that...

Others may hold the belief that...

It might seem that...

It is true that...

Admittedly,...

Opposing views claim that...

In the second half of the paragraph, following the presentation of the other side in support of it, signal to the reader that you will now turn back to your original thesis and refute your opponent's claims by stating why they are wrong. This step also will involve the skillful use of transitions. For example: 
Yet..

Nevertheless...

However...

This rebuttal (the turn back to your original position) needs to directly disagree with opposing argument stated in the first sentence of this paragraph and contain elaboration. Be sure to consider an explanation for why the counterargument is problematic or why it is less important than your argument.

Finally, write a conclusion sentence at the end of the paragraph to sum up your idea and link back to your thesis.

Here is an example of a counter argument paragraph which could be found in a report responding to this prompt we have seen before: On which part of the SWOT analysis should Company X focus in order to ensure its future success? Defend your choice.

Thesis: Company X should pay the most attention to their strengths, specifically the development of AppX technology, because they are currently the only company that uses this highly innovative technology.

Some may argue that Company $X$ should focus on the opportunity to expand into the Asian market. This market has over 2 billion young consumers, which is a huge potential market for Company X's products. By taking advantage of this opportunity, Company X could open the door to a global market and a large consumer 
base. However, this new potential market is currently saturated with Company X's competitors, many of them whom failed to make a profit last year. Focusing on AppX technology, a proven strength of Company $\mathrm{X}$, in a space with no current competitors is a far less risky move than seeking an opportunity elsewhere where the competition is stiff. Thus, investing in a current strength, is the wisest choice for Company X.

Note that the thesis, or writer's opinion, is in support of focusing on strengths, while the counterargument paragraph begins by presenting the argument that Company X should pay most attention to opportunities. The transition words in bold signal the turn away from and turn back to the thesis, and the conclusion of the writer.

Writing a counter argument is a skill that takes time to develop. With careful thought and planning, writers will become more adept at it, and therefore enhance their persuasion skills.

\section{Grammar}

English grammar is complex and filled with rules and exceptions to those rules. When thinking about learning or improving your grammar there are, of course, many aspects to consider, far more than can fit in this writing guide. Therefore, this guide focuses primarily on those most critical for writing clarity, based on our experience. 


\section{Agreement and Referencing}

There are two types of agreement in the English language: subjectverb and pronoun.

In English, subjects and verbs must agree, meaning that if you use a singular subject a singular verb must go with it. For example:

He goes to the store.

They go to the store.

Generally, this is pretty straight-forward for native speakers of English, yet in some instances it can be hard to know whether a subject is plural or singular. In the instances below, the subject of each sentence is singular and therefore takes a singular verb.

One of the members is absent.

The team leader, as well as his interns, is wellprepared.

The group with all the posters presents first.

Remembering whether a subject is singular or plural is a matter of memorization. The following words all require a singular verb: either, neither, each, everyone, everybody, anyone, anybody, no one, nobody, someone, somebody. For example: 
Each of the members contributes to the team.

Nobody was prepared for the emergency.

While incorrect subject-verb agreement will be noticeable to your reader, it likely won't confuse them. Lack of pronoun agreement or unclear pronoun referencing, on the other hand, has the possibility to cause confusion to the reader. Each pronoun must agree with the noun (antecedent) it represents and must clearly refer back to the noun it is meant to represent, as in the example below.

Mohammed finished his expense report then he went home.

It is clear that both "his" and "he" mean "Mohammed".

There are two main problems which can occur with pronoun referencing. The first is that there is more than one noun the pronoun could refer to. For example:

Nora and Maria worked diligently, and after more than a week she finished the project.

Not long after the company set up the subsidiary, it went bankrupt.

In the first sentence it is unclear who "she" is because "she" could 
mean either Nora or Maria. If they both finished the project, the pronoun "they" should be used. In the second sentence, the pronoun "it" could represent both the company and the subsidiary, which leaves the reader wondering exactly who went bankrupt.

The second potential problem with pronoun referencing is when the pronoun refers to a word that is implied, but not specifically stated. For example:

At $\mathrm{ABC}$, Inc. they go to great lengths to keep employees happy.

It can be inferred that "they" means the company, but it could also mean the supervisors, managers, or human resource department at $\mathrm{ABC}$, Inc.

Remember, pronouns need to clearly refer back to a noun and be in the same (singular or plural) form as the noun they are representing. In the case of referencing, if there is a doubt whether the pronoun does this, it is better to use the proper noun. In written work, being diligent about checking that each verb agrees with the subject of the sentence and that each pronoun correctly represents the noun it is intended to, is the best way to identify these errors.

\section{Tenses}

While there are more than 15 verb tenses in the English language. In academic writing, the most commonly used tenses are present simple, past simple and present perfect. Below are common situations when each tense is used: 


\section{Present Simple}

To introduce a topic

To make general statements that are still true

To state proven facts

For example:

A SWOT analysis is done to assess a company's strengths, weaknesses, opportunities and threats.

Kellogg's is a leading producer of breakfast cereals.

Americans eat more organic food than ever before.

\section{Past Simple}

To introduce past research

To describe how data were gathered

For example:

Chen and Li found that employer satisfaction with job performance was related to benefits the company offered.

To understand the market better, researchers interviewed 150 participants. 


\section{Present Perfect}

To connect the past to what is still relevant in the present For example:

The internet services industry has become more profitable over the years.

\section{Modals for making recommendations}

As a business professional, you will often be asked to make recommendations to your boss colleagues, and/or clients, either in writing or through a presentation. It's key to know which modal verbs to use that are both appropriate to the audience and the strength of the suggestion. First, consider your audience. If your audience is a superior, it's necessary to show respect to them by using a softer and less forceful tone.

For example:

You must invest in new equipment in order to increase profits.

You should invest in new equipment in order to increase profits.

The first example is very direct, too direct for a recommendation to a superior. The second example is a recommendation with the 
correct tone. In addition to using "should", the following words are in the appropriate tone to make a recommendation: suggest, propose, urge, advise. 


\section{Word Choice}

Deciding which words to use can be a tough choice, but in all cases, prioritize clarity. If your reader is not able to understand precisely what you mean, there will be a breakdown in communication.

\section{Collocations}

Collocations are word that commonly go together in English, and are known to "fit" together. A simple example is:

We solved the problem.

We answered the question.

However, if we switched the verbs in the two sentences and said "We solved the question", this isn't correct because "solve" and "question" don't collocate well together.

While varying your word choice by using synonyms can make your writing more interesting to read, if you do not have a keen awareness of the contextual uses of the word, you run the risk of error or incorrect meaning. For example:

An increase in sales will mean a bigger market share for our product.

An addition in sales will mean a bigger market share for our product. 
While "increase" and "addition" are synonyms according to Merriam Webster's thesaurus, the meaning of the two words is not precisely the same; "addition" sounds awkward in the sentence and even slightly changes the meaning, whereas "increase" is the correct word to describe a rise or fall in sales.

Awareness of words that fit well together is something native speakers of English often have because they've been exposed to the English language since childhood, while non-native speakers need to learn subtle uses of words. There are rarely strict rules that govern collocations, which also makes collocations challenging for non-native speakers. The best way to improve your knowledge of collocations is to expose yourself to English as much as possible, and to pay attention to which words are often used together. 


\section{Set phrases}

Like collocations, idioms, including the proper use of phrasal verbs and prepositions, are something that is learned with time and practice. For example:

Apply their knowledge into reality.

Put their knowledge into practice.

Both phrases are understandable, yet many native English speakers would say the second example just "sounds better", without really knowing why. There are some grammar rules surrounding these set phrases, but the majority of phrases have developed over time and are now considered standard usage. As with collocations, learning set phrases takes time and practice.

\section{Prepositions}

Prepositions are also a matter of memorization, which follow some, but not many predictable rules. Below are examples of correct usage of prepositions:

Spending on

Consumption of

Deadline for

Key points of

Take away from 
Increase/decrease in

Incorrect usage, for example, using "spending in materials increased over the period" can still be understood, but is not grammatically correct. Using the correct phrase is necessary for writing and speaking in a professional way, as in the case "spending on materials".

\section{Parallel Construction}

When listing items in a series, parallel grammatical construction must be used. Take the simple example:

Today, I'm going to shop for groceries, take a walk, and washing my car.

Today, I'm going to shop for groceries, take a walk, and wash my car.

The first sentence is not grammatically parallel because the third verb "washing" is not in the same form as the previous two; in the second sentence all three verbs are in the same form, present simple, so this sentence is parallel.

Parallel construction must be used in a series or list which is separated by commas, and uses the conjunctions "and" or "or", as in the above example.

Parallel construction also must be used within phrases. For example: 
They were advised they should focus on the company's strengths, they should cut costs, and a couple new positions should be created.

They were advised they should focus on the company's strengths, they should cut costs, and they should create a couple new positions.

The first sentence is incorrect because the third phrase is not parallel to the others, while in the second sentence the correct parallel construction is used.

Additionally, you can remove unnecessary words, and let "should" be the modal for all three verbs. For example:

They were advised they should focus on the company's strengths, cut costs, and create a couple new positions.

Parallel construction must also be used in the patterns of: between/ and, either/or, neither/nor, not only/but also. For example:

The management had to decide between investing in new equipment and buying back shares.They were advised to not only focus on the company's strengths, but also cut costs.

In the first sentence, "investing" and "buying" are parallel. In the 
second, "focus" and "cut" are parallel. Both of these sentences are grammatically correct.

Tip: The best way to ensure your sentences are parallel is to pick out all the conjunctions in your writing and look at the series before and after the conjunctions. Each item in a series must be in the same grammatical form.

\section{Transition Words}

Transition words are conjunctions, or connecting words, that establish connections between sentences and between paragraphs. The purpose of transition words is to guide your reader through your report to reach your intended conclusion. Transition words do this by showing the logical connection and the relationships between ideas. For example, if you want to contrast two ideas, the word "however" can be used, while in comparing ideas the word "likewise" can be used. Using the correct transition clarifies your meaning, but using the wrong transition can confuse your reader. For example:

The profits of Company X increased in the second quarter compared to the first quarter, likewise revenue declined.

In the example above, the transition "likewise" is incorrect because it signals to the reader that what comes both before and after the transition word will be the same or similar. This isn't the case however, because profits increased yet revenue declined. The correct transition here would be "however".

This site link provides a comprehensive list of transitions and their uses. 
Use of transition words does not necessarily mean that a report will be easy to follow. In fact, transitions used incorrectly or overused can make the organization of a report less clear and leave the reader confused, as in the example above. Transitions themselves cannot replace good organization, rather proper organization needs to come first and transitions then enhance the organization.

Transition words can also be overused, and if they are, they can be a distraction to the reader. Transition words are often encouraged among immature writers because they mark ideas, yet when writers develop, it is no longer necessary to mark each sentence with "first...second...third" In some cases, very few if any, transitions are needed to make a report flow well. If you read publications like the Wall Street Journal or New York Times, you will notice how few transition words are used. Instead of using transition words to connect ideas, strong writers use other methods. Note that in the excerpt from The New York Times below, only one transition phrase is used, which is "for example".

On Thursday, Apple became the first publicly traded American company to be worth more than $\$ 1$ trillion when its shares climbed 3 percent to end the day at \$207.39. The gains came two days after the company announced the latest in a series of remarkably profitable quarters. Apple's ascent from the brink of bankruptcy to the world's most valuable public company has been a business tour de force, marked by rapid innovation, a series of smash-hit products and the creation of a sophisticated, globe-spanning supply chain that keeps costs down while producing enormous volumes of cutting-edge devices. That 
ascent has also been marked by controversy, tragedy and challenges. Apple's aggressive use of outside manufacturers in China, for example, has led to criticism that it is taking advantage of poorly paid workers in other countries and robbing Americans of good manufacturing jobs. The company faces numerous questions about how it can continue to grow.

The following are additional ways of connecting ideas, as highlighted in red in the example:

Pronouns- "it's shares" refers to Apple's shares; "that ascent" means "the ascent from the brink of bankruptcy".

Substitution- "the gains" refers back to "shares climbed 3 percent"; "the company" is used twice, both times to reference Apple.

Using transition words in moderation, along with substitution and pronouns, make a report flow logically, rather than make the reader bored or confused. As you develop as a writer, be intentional about balancing your transition words with the other methods of organization.

\section{Writing Concisely}

Well-known author, George Orwell said, "If it's possible to cut a word out, always cut it out". This doesn't mean never write the word, rather in the editing process, search for and cut out words which don't add value to your work.

Good writers are able to express their intended meaning without 
using unnecessary words. In business writing in particular, being clear and concise needs to be prioritized over being fancy and wordy. Busy executives have no time to mull over long, complex sentences when a short version is clearer and provides the same meaning.

Many writers find it easier to initially write from stream of conscience, including many transition phrases such as "I intend to tell you...", "My first claim is...", "The second thing is...", and "My final analysis shows". However, as stated in the revising section, these extra words and phrases should eventually be eliminated. Most often, they can be deleted without any other modification to the sentence. For example:

I intend to show you why good writing is always worth the effort.

I intend to show you why Good writing is always worth the effort.

In this fashion, we've reduced the sentence by six words (24 characters or $45 \%$ including spaces), without changing its meaning, and the sentence is more powerful in the process.

Whereas writing every word that comes to mind is fairly easy to do, writing concisely is more challenging and takes considerably more time and effort. You must be intentional about each word you write and ask yourself whether it serves a purpose. Consider whether one word could replace several and if a shorter word could replace an unnecessarily long word. Consider whether entire sentences, paragraphs, or even sections could be eliminated. However, you must find a balance between being concise and eliminating too much. Cutting out too many words could leave your 
reader confused about the connections between ideas or unable to follow your logic.

Use the following steps to help you write more concisely:

1. Eliminate redundancy. If one word has a similar meaning to another in the same sentence, delete one. It's not necessary to say the same thing twice. For example:

Carrots contain a wide range of various nutrients.

Carrots contain various nutrients.

The meaning of "wide range of" and "various" is the same, so using both is redundant. Similarly, in the example below, "some of the various methods" does not add value to the sentence and should be removed.

She explained some of the various methods of doing an analysis.

She explained the methods of analysis.

2. Be specific with qualifiers. Qualifiers are almost always vague in nature. For example:

The CEO proposed several new changes and most of the board somewhat agreed. 
What does "several" mean? It could mean 3 or 6 changes. How many is "most of"? These words adds no value to the sentence because they are too vague.

In business writing, before using any vague qualifier, consider whether a qualifier could be replaced with data. For example:

The CEO proposed 4 changes and $80 \%$ of the board agreed.

The word "somewhat" could easily be removed because it is not essential to expressing the author's intended meaning and could not be replaced by any concrete data. By removing this and quantifying the other words, the sentence becomes less wordy and the meaning is clearer.

3. Reduce prepositional phrases. Too many prepositional phrases in the same sentence can make the sentence hard to read. The word "of" is commonly overused, and can often be replaced by an adjective and noun or by making a noun possessive. For example:

Original: The collection of data was a process that consumed a lot of time.Revised: The data collection was time consuming.

Original: The reason for the failure of the new system was lack of knowledge of users.

Revised: The new system failed because the users lacked knowledge. 
The prepositions "in", "for", "at", "on", and "over" should also be examined to determine whether they are necessary. For example:

The reason for the failure was that the team didn't address the needs of the customers.

The failure was caused by overlooking the customer's needs.

4. Use verbs to show action. To best emphasize the importance of the action, it is best to use strong, rather than weak verbs. The verbs "do", "is" and "have" are considered weak because though they have a purpose in the sentence, they don't convey an action. In the example below, the verb "do" should be replaced by the verb "evaluate", which is stronger. This also eliminates a preposition and does not change the meaning of the sentence. Use strong verbs, whenever possible.

We need to do an evaluation of the candidates.We need to evaluate the candidates.

5. Reconsider the use of vague nouns. Words like "factor", "aspect", "situation", and "area" are often vague. For example:

Original: In the areas of business related to finance, an 
understanding of mathematics is key.Revised: In finance, understanding mathematics is key.

Original: Salary is an important factor to consider when choosing a job.

Revised: Salary is important to consider when choosing a job.

Vague nouns can often be removed without altering the meaning of the sentence. If it is possible to remove a vague noun, do so.

Throughout the writing process and especially before submitting a report, check every word to make sure it adds value to the sentence; if it does not, remove it. Writing concisely takes dedication. It does not come naturally to many people, but is a skill that must be practiced and refined over time.

\section{Active Voice}

The essential needs in business writing are communication and action. In active voice, the emphasis is on the doer of the action so the subject that performs the action typically comes before the verb. The object that receives the action typically comes after the verb, and therefore has less emphasis. By using passive voice the writer is conveying that the object is more important than the subject or that the subject is not known. In business writing, because it is generally necessary to know clearly who (subject) is doing what (verb), using active voice is preferable.

Additionally, it takes more words to write passively than actively so writing in an active voice will make you write concisely. For 
example, the following two sentences express the same meaning, but active voice uses $25 \%$ fewer words than passive voice.

Passive Voice: The quarterly earnings for XYZ Corp were announced.

Active Voice: XYZ Corp announced its quarterly earnings.

Thus, avoid passive construction unless it is absolutely necessary.

However, there are few situations when passive voice is necessary. One is if the doer of the action is not known. For example:

Passive Voice: Their house was broken into.

In this case, we do not know who performed the action, so passive voice is appropriate.

In the majority of business writing situations, passive voice is not appropriate because the doer of the action is known. In the example below, there is no reason to use passive voice.

Passive Voice: The meeting was led by the management team.

Active Voice: The management team led the meeting. 
Active voice above is preferable because the doer of the action is the subject of the sentence. Before using passive voice, ask yourself if it is necessary. If it is possible to use active voice, do so.

\section{Tables and Figures}

For ideas that are particularly important to your report, consider creating a graphic, figure, or image to illustrate. For example, in the Introduction of this textbook we used the Indexed line drawing cartoon from author Jessica Hagy because it aptly illustrates the task ahead for the aspiring business writer. We also used an hourglass graphic to illustrate the Essay Template because the shape seems useful in conveying the narrowing and broadening process of report writing. Similarly, there is a SWOT Checklist in Chapter 4 because it can serve as a convenient tool in creating your own SWOT analysis. You may find such tables and figures help you make your point effectively in a report.

When including graphics like we used in your report, place them where they can be easily referenced by your reader. Such figures should be numbered (e.g., Figure 1) and given a descriptive title for reference in the body of the report. If the illustration is larger than a single page (for instance a financial report), or if it is only tangentially related to the main topic of your report (for instance an off topic, but potentially emergent opportunity), place it in an appropriately named appendix.

But, don't overdo things. When included, a spreadsheet or diagram should explicitly illustrate your thinking and communicate your message. Superfluous illustrations "pad" the report and distract from its value. Never include a figure without accompanying narrative to explain its meaning. 


\section{Appendices - A Note on End Matter}

In the process of researching, writing, and editing your report, it is common to identify a number of items that belong with the report but not necessarily in it. This is where the end matter comes in. For purposes of business writing, we refer to the items that come at the end of your report as appendices (plural) or an appendix (singular). As the title of this section suggests, appendices belong at the end of the report and are not generally considered in the word or page count of your report unless indicated otherwise. Usually, you will have no appendix or only one. If you use an appendix use the title of "Appendix: [describe the content]". However, for complicated reports, you might have multiple appendices. In this case, number the appendices as "Appendix X: [describe the content]" where " $\mathrm{X}$ " denotes the order in which it appears using capital letters starting with "A".

In rare cases you may also want to include entire pieces of external matter, e.g., a financial statement from a subject, an extended description of a technical process, or a project work breakdown structure. These each deserve their own appendix.

\section{Actionable Recommendations}

Although there are definite exceptions, many of your business school assignments will ask you to study a pile of data (or a case), apply a business model or two, and make a recommendation. In the business world, this last part-making recommendations-is generally what matters. If you make good recommendations, you may be a star. Bad ones can label you as someone to ignore. What you recommend is always important. Sometimes, how you recommend matters too. 


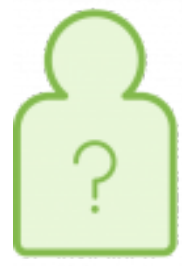

Who...

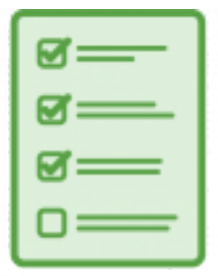

does what. . .

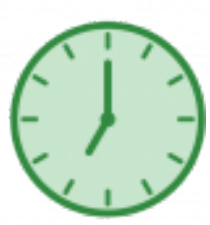

Figure 3.4

Actionable

Recommenda

tions

The quality of your recommendations is a direct result of the thoroughness with which you prepared the analysis. Recommendations are directed at solving whatever problem the client is facing. Your recommendations should be in line with your analysis; that is, they should follow logically from the observations and data you provide in the report.

However, making your recommendations actionable means that you provide specific, measurable, and detailed instructions that are likely to produce positive results for the client. Think in terms of who does what by when? Ask yourself, will my client be able to implement these proposed recommendations in my absence or will they just scratch their heads. Your actionable recommendations should answer the questions how and how much? Make your proposal as complete as possible given the time and information constraints.

Coincidentally, this practice of who-does-what-by-when, has another application. If you find yourself in a position of delegation, getting commitment on these three elements of any promise will eliminate most surprises. By promises, we mean an agreement from a colleague, superior, or subordinate to follow-up, investigate, or perform any action. This is because these three conditions cover most excuses for not acting. For example, a fellow student who was assigned to edit the final draft of your report says "I didn't think this was my responsibility." Or, that same miscreant claims "That's not what I thought needed to be done." Or possibly, he says "I thought 
I still had more time." This simple action-focus of who-does-whatby-when, especially when done in writing by all involved parties, will go a long way toward preventing many group collaboration problems. 


\section{Writing and Business Models}

Those who can write will work for those who can't. Anonymous In our teaching, we are often asked by students to provide examples of the topics we are covering. Often, such examples are seen by those same students as the "correct answer" to the whatever question is being addressed. This is rarely the case in school and never the case in the business world. In both realms, samples are provided to help the analyst (or student) get started. The circumstances of the problem (or assignment) should always dictate the final outcome.

This chapter is intended as a culmination of everything that comes before it. It is not an exhaustive treatment of common business models. That would be daunting! Instead, these models are discussed as examples of how a business student might use them in conducting an analysis and writing a report.

Crafting these examples required first understanding a specific business model, comparing the components of the model to the facts of a specific case to make precise conclusions, and finally writing about these observations in concrete language. Such a linear and systematic approach to the application of a business model is an example of demonstrating critical thinking. In the business world, this type of thinking and reasoning is expected. In its absence, the author is judged incompetent and may eventually lose their job. In the academic world, this is the kind of thinking that separates the "A" student from their peers.

\section{Why Use a Model?}

Many a problem has been solved simply by asking the right question. In the business world, our experience has shown that having an 
analytical model is one of the single best predictors of successfully finding a workable solution. That's one reason why in the academic world, students are exposed to many and varied analytical models. Models help you know what questions to ask, what questions are out-of-scope, and most importantly, when you are done.

Whether it is ethics, marketing, finance, strategic management, or any other topic, there is probably a model that will fit the situation. And because business students have this exposure and knowledge, analysis is one of the most marketable skills you can demonstrate to an employer. While in school, it is simply a tool in the first part of the writing process.

Prior to teaching, John worked at a large consumer electronics manufacturing and marketing company. One task he took on was to lead a global project to standardize problem solving across the many divisions of the company. The logic behind the project was simple, yet ambitious-identify a universal and standardized approach to speed up the time-to-resolution when engineers from different business units came together with a common problem. The justification for the project was that different approaches, and sometimes conflicting terminology, for solving technical problems was interfering with the ability of engineers and scientists to collaborate and solve problems quickly.

Step one was to identify the primary methodologies, find a champion to speak for each, and bring those experts together for a conversation. An exhaustive survey of the company found some $120+$ unique problem solving methods. Fortunately, they could be grouped into a dozen camps such as those based on Kepner-Tregoe (KT), those related to TRIZ, ones using a Six Hats approach, etc. For example, a KT approach might involve an extra step if used for research and development rather than production, but they still started with identifying a root cause. After some discussion among these camps, each identified one or two spokespersons to represent their approach in deeper discussions.

These representatives agreed to an evidence-based approach of study. That is, each would go to their respective operating 
practitioners to create an inventory of when their specific approach was used effectively to solve a technical problem and to both categorize and quantify (in monetary terms) the outcome. After a couple months of research, the group came back together and compared results.

Unfortunately, what was supposed to be a straightforward comparison of investments and their returns in terms of time and money was a much more complex exchange of difficult-to-compare outcomes. It appeared that all twelve approaches were roughly equivalent in efficacy. Whenever a group undertook solving a problem using any of the approaches or one of its derivatives, they typically came to a satisfactory conclusion. This contrasted many examples of attempts to solve problems that were not supported by a formal approach. In other words, experts taking a trial-anderror approach to finding a solution took longer and were less likely to find a solution than a group that systematically used one of the dozen problem solving methodologies or one of its derivatives.

Eventually, the group disbanded with an unexpected conclusion. While we reported to management that a single approach was not advised, we advised using any formal approach to solving problems would make a significant positive difference when compared to not using one. As this story relates to the textbook's current chapter therefore, we advise using a business model when writing business case responses. Doing so means you will make fewer mistakes of omission and will create a significantly more robust answer than if you don't use one. Read on for some examples of how this can be done effectively. 


\section{Example $\mathbf{~ - ~ S W O T ~}$}

\begin{tabular}{|c|c|c|}
\cline { 2 - 3 } \multicolumn{1}{c|}{} & $\begin{array}{c}\text { Positive } \\
\text { Identifiers }\end{array}$ & $\begin{array}{c}\text { Negative } \\
\text { Identifiers }\end{array}$ \\
\hline $\begin{array}{c}\text { Internal } \\
\text { Focus }\end{array}$ & Strengths & Weaknesses \\
\hline $\begin{array}{c}\text { External } \\
\text { Focus }\end{array}$ & Opportunities & Threats \\
\hline
\end{tabular}

Figure 4.1

Elements of

SWOT

Analysis

SWOT stands for strengths, weaknesses, opportunities, and threats; it is typically one of the first models to which business students are exposed. Some students, however, may not be familiar with the tool. When used, it is expected that strengths and weaknesses are internal to an organization, that is their unique resources, assets, and capabilities either point to what the organization is good at or where it is vulnerable; they are the conditions to which the organization has some measure of control. Opportunities and threats, on the other hand, always come from outside the organization and are indicative of events or circumstances to which the firm may or should respond. They happen in the external environment and are beyond the control of the firm.

By the way, we use SWOT analysis for numerous examples in the book, especially in connection with Bloom's levels of learning. Because we rely on knowing this model, we included an example of the useful checklist in this description. These are items that often appear in a SWOT analysis. Obviously, each analysis will be unique to the specific organization studied, but these questions are typical of those asked to discover the many factors that can impact an organization.

Figure 4.2 - SWOT Checklist. 


\begin{tabular}{|c|c|}
\hline Potential Internal Strengths & Potential Internal Weaknesses \\
\hline Many product lines? & Obsolete, narrow product lines? \\
\hline Broad market coverage? & Rising manufacturing costs? \\
\hline Manufacturing competence? & Decline in R\&D innovations? \\
\hline Good marketing skills? & Poor marketing skills? \\
\hline $\begin{array}{l}\text { Good materials management } \\
\text { systems? }\end{array}$ & $\begin{array}{l}\text { Poor material management } \\
\text { systems? }\end{array}$ \\
\hline R\&D skills and leadership? & Loss of customer goodwill? \\
\hline $\begin{array}{l}\text { Information system } \\
\text { competencies? }\end{array}$ & $\begin{array}{l}\text { Inadequate Information } \\
\text { systems? }\end{array}$ \\
\hline Human resource competencies? & Inadequate Human resource? \\
\hline Brand name reputation? & Loss of brand name capital? \\
\hline Portfolio management skills? & Bad portfolio management? \\
\hline $\begin{array}{l}\text { Cost of differentiation } \\
\text { advantage? }\end{array}$ & Loss of corporate direction? \\
\hline $\begin{array}{l}\text { New-venture management } \\
\text { expertise? }\end{array}$ & Infighting among divisions? \\
\hline Appropriate management style? & Loss of corporate control? \\
\hline $\begin{array}{l}\text { Appropriate organizational } \\
\text { structure? }\end{array}$ & $\begin{array}{l}\text { Inappropriate organizational } \\
\text { structure? }\end{array}$ \\
\hline Appropriate control systems? & Inappropriate control systems? \\
\hline $\begin{array}{l}\text { Well-developed corporate } \\
\text { strategy? }\end{array}$ & High conflict and politics? \\
\hline Good financial management? & Poor financial management? \\
\hline Others? & Others? \\
\hline $\begin{array}{l}\text { Potential Environmental } \\
\text { Opportunities }\end{array}$ & Potential Environmental Threats \\
\hline Expand core business? & Attacks on core business? \\
\hline Exploit new market segments? & $\begin{array}{l}\text { Increases in domestic } \\
\text { competition? }\end{array}$ \\
\hline Widen product range? & $\begin{array}{l}\text { Increase in foreign } \\
\text { competition? }\end{array}$ \\
\hline
\end{tabular}




\begin{tabular}{|c|c|}
\hline $\begin{array}{l}\text { Extend differentiation } \\
\text { advantage? }\end{array}$ & Change in consumer tastes? \\
\hline $\begin{array}{l}\text { Diversify into new growth } \\
\text { businesses? }\end{array}$ & Fall in barriers to entry? \\
\hline Expand into foreign markets? & $\begin{array}{l}\text { Rise in new or substitute } \\
\text { products? }\end{array}$ \\
\hline Apply R\&D skills in new areas? & Increase in industry rivalry? \\
\hline Enter new related businesses? & $\begin{array}{l}\text { New forms of industry } \\
\text { competition? }\end{array}$ \\
\hline Vertically integrate forward? & Potential for takeover? \\
\hline Vertically integrate backward? & Existence of corporate raiders? \\
\hline Enlarge corporate portfolio? & $\begin{array}{l}\text { Increase in regional } \\
\text { competition? }\end{array}$ \\
\hline Overcome barriers to entry? & $\begin{array}{l}\text { Changes in demographic } \\
\text { factors? }\end{array}$ \\
\hline $\begin{array}{l}\text { Reduce rivalry among } \\
\text { competitors? }\end{array}$ & Changes in economic factors? \\
\hline $\begin{array}{l}\text { Make profitable new } \\
\text { acquisitions? }\end{array}$ & Downturn in economy? \\
\hline $\begin{array}{l}\text { Apply brand name capital in } \\
\text { new areas? }\end{array}$ & Rising labor costs? \\
\hline Seek fast market growth? & Slower market growth? \\
\hline Others? & Others? \\
\hline
\end{tabular}

\section{Scenario}

Students in a case study-based course were provided a briefing on a British firm, Hewden, that rents heavy excavation and building equipment for large construction projects. The brief contained a pre-completed SWOT analysis of the company. The assignment required students to analyze the artifact from an actual Hewden- 
generated SWOT analysis in order to respond to the assignment prompt.

\section{Data}

These data were copied from the case briefing, but not in their entirety. As a case study, this document is four pages long.

Strengths:

- strong brand and reputation

- market leading training and development opportunities

- flat organizational structure

- fun working environment where employees thrive professionally and personally

- dedicated, loyal workforce and high number of long-serving professionals

- Core Fleet Guarantee (any order received before midday is delivered the next day)

Weaknesses:

- an have an outdated operating system that prevents network visibility to rental equipment inventory

- logistical challenges and site-to-site variability of quality of service

- inefficient operations with variable levels of service quality

- increasing strength of competition

- poor implementation of a new operating system

- an aging workforce threatening to leave key positions vacant or underperforming

Opportunities:

- use social media to create a strong bond with customers

88 | Writing and Business Models 
- use social media to improve recruitment

- use electronic channels to allow employees to interact directly with the CEO

- Hewden Smartphone app to make the rental process smoother and more efficient

- PDA handsets trial for tracking and collecting rental equipment

- improved inventory availability via the new operating system

- positive, growth oriented employee culture for advancement

Threats:

- due to its excellent training programs, competitors are keen to recruit Hewden's employees

- economic factors

\section{Prompt}

Identify one of Hewden's strengths, weaknesses, opportunities, or threats. Compose a persuasive argument for how that factor will make the biggest impact on the firm's success.

\section{Approach}

Although not specifically named, the prompt is obviously calling for a SWOT analysis because it uses the words-without the acronym. Already, the wording of the prompt requires the student to at least understand the model (even though the verb "identify" is an indication of the knowledge level, it is used in such a way that requires a deeper understanding of the model, Bloom's comprehension level). The second verb, "compose", gets more difficult because it requires the student to write a persuasive 
argument. Not only must the student comprehend and apply the SWOT model, they must distinguish between the various factors identified in the case brief in order to distinguish one from all the others and they must write persuasively about it (Bloom's evaluation level). To build a strong case, the student is even touching on Bloom's synthesis level.

The case was written in 2011, three years into a major global recession. You could perform an internet search and discover the subject company went out of business in late 2016, after Great Britain voted to exit the European Union. However, the student must approach the case report as if it is still 2011 and knows only what is known as of the time of the writing. As students of history, we have the benefit of time and perspective, but nobody can travel to the future to know if they are making the right choices. Sometimes, knowing the eventual outcome of a decision set spoils one's ability to think openly and creatively about what options are best. It is best to write your report in school before you, figuratively, peak to the end of the book and discover the ending.

\section{Report}

At first, this prompt seems relatively simple, but on deeper analysis it requires a high level of thinking and understanding of business conditions. The case is far reaching. The prompt is open ended and there is sufficient data in the brief to pursue any one of the factors as making the biggest impact. It is possible to use a lower level of thinking (application and analysis), but the best students go to higher levels of thinking (analysis and synthesis). This example uses Bloom's synthesis level.

The Great Recession created a contraction in Britain's GDP of $.5 \%$ in 2008 and $4.2 \%$ in 2009. In the two years since, the recovery was very modest with GDP growth of only $1.7 \%$ in 2010 and $1.5 \%$ in 2011. Although the case does not provide data on Hewden's actual 
profitability, we know from the country's Office for National Statistics that profits were at historical lows and trending down but at a slower rate (i.e., possibly stabilizing); we can assume the same was true for Hewden. The case points to an outdated operating system that was causing the firm to lose track of its equipment and, as a result, experience a falling quality of service. It was also losing money from ineffective training results in trying to convince employees to use the replacement system. We also know this is resulting in losses due to its Core Fleet Guarantee. Hewden should prioritize the implementation of its operating system to reduce costs, increase efficiencies, and improve performance.

Despite increasing lapses in the Core Fleet Guarantee, it remains an asset and Hewden continues to enjoy a strong brand. Putting more resources behind the implementation of its operating system will improve operating efficiencies, better utilize expensive capital assets (equipment), curtail losses associated with the Core Fleet Guarantee, and reinforce its Core Fleet Guarantee.

Hewden's financial security is already under stress due to global economic factors; these factors have continued to worsen. No firm can sustain negative financial performance indefinitely. The external threats posed by the current economic environment are critical and demand Hewden's immediate and highest priority. If ignored, the economy promises to overwhelm Hewden and cause it to cease operations. If properly addressed, however, these same factors could be turned into opportunities for the firm. The SWOT analysis exposes several options for reducing external threats, unfortunately threats are outside of the control of company, so they must be addressed indirectly by through cutting costs, leveraging brand strength, and investing for the future.

\section{Example 2 - Porter's Five Forces}

Understanding the competitive environment in which a company 
operates is essential for deciphering how and why a company makes the decisions it does. In 1980, a Harvard professor, Michael Porter, proposed such a model in describing five universal forces present in all markets that will impact the likelihood of any firm in the industry making a profit. Importantly, these forces behave independently and are rarely reciprocal nor symmetrical; meaning, four forces may be strong but the fifth force may be sufficiently weak as to offset them. The unique blend of these forces in any market or industry directly impacts the ability of existing firms to make a profit and therefore the attractiveness of the industry. That is, if profits are easy to come by, the industry is attractive; if they are difficult to achieve, the industry is deemed unattractive.

These forces are roughly defined as:

Threat of New Entrants - the barriers protecting existing companies in a market from having to compete with new companies not previously present in the industry. These barriers to entry can be in the form of capital costs, network effects, customer switching costs, brand loyalty, government regulations, and likelihood of retaliation. Conversely, an industry will naturally attract new entrants when existing participants are easily making a strong profit.

Buyer Bargaining Power - the strength of a buyer's negotiating position is enhanced when the following conditions exist: buyer is in a position to easily switch their purchasing loyalty to other firms; the product sold by the industry has very few differentiating features; or the industry is struggling to find buyers. When buyers have control or power, the market-and the rivals within the market-are more likely to compete for their purchase.

Supplier Bargaining Power - similar to buyers, supplier power is strongest when: they are more concentrated, maybe even a single source supplier; they alternative buyers than the industry being studied; or when their products are highly differentiated. When suppliers have control or power, they will leverage their position in purchase negotiations and will have a strong influence on what members of the industry must pay for their supplies. 
Threat of Substitutes - when an industry's buyers can find attractive price-to-performance trade-offs by buying outside of the current industry, the threat of those substitute products impacting the profitability of all competitors in the industry is high.

Degree of Rivalry - separate from each of the previous forces, this force reflects the extent and intensity to which rivals in a market will compete with each other. When industry growth is slow, fixed costs are high, products or services are not differentiated, and exit barriers are high, then rivalry will be great.

\section{Scenario}

Students in a capstone strategy course completed a multi-round computer simulation pitting teams against each other manufacturing and selling a fictional product, called "Micromatic". After eight rounds (referred to as quarters) of competition, students were provided a copy of results for the class (referred to as the subject industry). This allowed students to have experience with one company during the competition and to have access to all of their competitors data once the simulation was complete.

\section{Data}

The data provided here is not exhaustive, but is representative of what the simulation created and is useful in generating the report at the end of this example. The subject industry is \#3 in Figure 4.3. All five comparison industries (previous terms of the same course) are different in size in that they had different numbers of competitors and different durations (quarters), therefore, both absolute and average data are provided. The industries are sorted from top to bottom in terms of Total Industry Net Income over the entirety 
of the simulated competition which roughly (but not exactly) translates into the percent winners column-the percent of winners reflects how many companies were generating a profit at the end of the simulation versus how many were generating a loss.

Figure 4.3 Comparison Industry Data for Example 2

\begin{tabular}{|r|c|c|c|c|c|}
\hline \multicolumn{5}{|c|}{ Total Industry } & \multicolumn{2}{c|}{ Avg Qtrly Company } \\
No. & \multicolumn{2}{|c|}{ Revenue } & \multicolumn{2}{c|}{ Net Income Winners } & \multicolumn{2}{c|}{ Revenue } & Profit \\
\hline 1 & $\$ 248,945,181$ & $\$ 8,531,255$ & $91 \%$ & $\$ 1,740,875$ & $\$ 59,659$ \\
\hline 2 & $\$ 189,994,220$ & $\$ 4,737,919$ & $89 \%$ & $\$ 1,623,882$ & $\$ 40,495$ \\
\hline 3 & $\$ 295,094,514$ & $\$ 3,708,871$ & $\mathbf{6 4 \%}$ & $\mathbf{\$ 1 , 6 2 1 , 3 9 8}$ & $\mathbf{\$ 2 0 , 3 7 8}$ \\
\hline 4 & $\$ 202,766,287$ & $\$ 2,254,445$ & $60 \%$ & $\$ 1,689,719$ & $\$ 18,787$ \\
\hline 5 & $\$ 200,270,040$ & $\$ 1,853,198$ & $69 \%$ & $\$ 1,711,710$ & $\$ 15,839$ \\
\hline & & & & & \\
\hline Avg & $\$ 227,414,048$ & $\$ 4,217,138$ & $74 \%$ & $\$ 1,677,517$ & $\$ 31,032$ \\
\hline
\end{tabular}

\section{Prompt}

Using Porter's Five Forces, examine the subject industry to assess its attractiveness. 


\section{Approach}

The wording of the specific prompt requires the student to use Porter's model to define attractiveness. A student could-and many often do-define the term attractive in their own words or using an online dictionary and go from there. This is an approach similar to the story in the Introduction of the book when engineers jumped into solving technical problems by using trial-and-error. The outcome can be persuasive, but often will miss key elements or fail to fully answer the question. Porter has been recognized as a leading expert for many decades and his framework is likely to yield a superior outcome. The instructor has provided a clue to get students started using the appropriate business model.

\section{Report}

This report takes the described approach, examines the data using Porter's framework, and provides a complete report. Given Porter's model and the nature of the prompt, some of the response will be derived from the hard data and other portions will rely on the experience of the student while assessing the simulation decisions. The prompt is an example of Bloom's synthesis level of thinking.

To determine the attractiveness of the simulated industry, we must identify the possibility for any company in the industry to generate a profit; if the opportunity is great, the industry is attractive. Michael Porter's Five Forces model for analyzing a market's structure is a useful tool for answering this question.

Looking first at the threat of new entrants, the field of competitors remained static throughout the simulation. No new companies entered the competition. However, while the average company in the industry earned about $\$ 20 \mathrm{~K}$ in profit each quarter - a positive outcome relative to two industries - this result is 
mediocre relative to the other two comparative industries which saw profits two and three times greater at $\$ 40 \mathrm{~K}$ (Industry \#2) and $\$ 60 \mathrm{~K}$ (Industry \#1) per quarter. While there is a moderate threat of new entrants due to a positive average net income, there are clearly more attractive opportunities in other industries.

Our industry had eight competitors, each selling roughly identical products. While there was some differentiation between the companies' products, this differentiation was insufficient to prevent customers from switching when prices and features or quality warranted. In the fifth quarter of play (Q5), the winner (Team \#3) increased its price across all three regions by $\$ 3 /$ unit while keeping all other marketing factors the same as the previous quarter; actual demand dropped a total of 10,054 units. In the following Q6 they dropped the price by $\$ 5 /$ unit while again keeping all other factors the same and demand across all three regions increased by 15,848 units. We saw similar effects across the entire industry suggesting buyers are very sensitive to price and indicating their bargaining power was high.

The bargaining power for suppliers to the industry was similarly high. Although industry rivals could effectively lower the cost of raw materials from the industry's sole source supplier by placing larger orders, this opportunity was available to all industry competitors. While the supplier did not aggressively exercise its bargaining position, by definition the nature of the supplier's relationship to the industry meant its bargaining power is strong.

While the threat of substitutes was never a reality in our simulation - demand for substitute products would have meant a drop of demand for the entire industry without recovery - its possibility probably had a moderate impact on the industry. However, the relatively modest income potential per company per quarter (third of five industries, about $\$ 20 \mathrm{~K}$ ) and the modest $7 \%$ increase of the average unit price across all companies and the entire eight quarters of simulation (from \$70/unit in Q1 to \$75.20/ unit in Q8) suggests the industry was vigilant to external substitute products. 
Finally, and most telling, was the intensity of rivalry in our industry. This was a strong factor impacting the likelihood for any one firm's ability to make a profit. Indeed, the $64 \%$ of winners in our industry compared to the other four industries was second lowest and compares negatively to the overall average of $74 \%$. Only three of the eight companies were able to operate without emergency loans from the bank, only one firm was paying a dividend to its shareholders, and marketing expenses were consistently increasing throughout the competition (a total of $41 \%$ increase from $\$ 242 \mathrm{~K}$ in Q1 to $\$ 341 \mathrm{~K}$ in Q8) indicating firm's were struggling to retain their customer's business.

Overall, with strong bargaining positions for both buyers and suppliers and a high degree of rivalry within the industry, the average company in this industry struggles to make a profit. Therefore, this industry is not attractive. 


\section{Example 3 - BEP Analysis}

Most students learn about break-even point (BEP) analysis very early in the business education. The concept is relatively simple,

\section{Scenario}

In the same course as Example 2, in which capstone students were asked to define the attractiveness of a simulated industry, students were provided a set of data and asked to define the BEP for a specific firm. Essentially, BEP is the level of production required by a firm in which revenue will cover expenses and generate no profit or loss, to literally break-even. The analysis requires the student to differentiate between fixed and variable costs associated with production. Fixed costs are those that are not impacted by volume. In other words, whether the firm sells a million units of product or none at all these expenses are the same; for example the building, equipment, and machinery a plant requires to produce the product are variable costs. On the other hand, variable costs are impacted by volume; variable costs go up as volume increases and decline as volume decreases. Variable costs include items like direct raw materials, labor, and utilities.

To calculate BEP, the student must know the total volume in units, the average price in units, the variable cost per unit, and the total fixed costs. Using this data and the following two formulas, the BEP is calculated. The answer to the first equation is used as an input for the final equation.

$$
\begin{aligned}
& \text { Contribution Margin = Average Price }- \text { Variable Cost } \\
& \text { Break-Even Point }=\text { Fixed Costs } / \text { Contribution Margin }
\end{aligned}
$$




\section{Data}

All data must come from a single point in time. In this case, data were collected for one company (referred to as Company \#3, the winner for the simulation) at the end of the 8th quarter (referred to as Q8).

Figure 4.4 BEP Data for Example 3

\begin{tabular}{|l|r|l|l|}
\hline Total Volume & $\begin{array}{r}39,898 \\
\text { units }\end{array}$ & Fixed Costs & \\
\hline Average Price & $\$ 73 /$ unit & $\begin{array}{l}\text { Accumulated } \\
\text { Depreciation }\end{array}$ & $\$ 40,000$ \\
\hline Variable Costs & & Short-term interest & $\$ 1,250$ \\
\hline $\begin{array}{l}\text { Subcontract and } \\
\text { Raw Materials }\end{array}$ & $\$ 422.380$ & Bond Interest & \\
\hline $\begin{array}{l}\text { Labor, Quality, } \\
\text { Overhead }\end{array}$ & $\$ 1,521,177$ & Plant and & $\$ 4,875$ \\
\hline $\begin{array}{l}\text { Warehouse } \\
\text { Operations }\end{array}$ & $\$ 39,317$ & Lease Payment & $\$ 15,000$ \\
\hline & & $\begin{array}{l}\text { Selling and } \\
\text { Administrative (S\&A) }\end{array}$ & $\$ 331,000$ \\
\hline
\end{tabular}




\section{Prompt}

Calculate your company's break-even point at the end of the simulation (Q8) and assess the implications of your BEP on future decisions if the simulation were to continue for four more quarters.

\section{Approach}

The first portion of the report is relatively easy as it is a plugand-chug activity of putting the correct data into the formula and calculating a number. The second part is a bit more challenging in that they must explain the implications of the answer they derived. In the first "calculating" part, the student must still use critical thinking; that is, if the calculated number does not look right-too high or too low-the student should check their math or look for errors in what data was included.

Once sure they have a reasonable set of figures, however, the student can demonstrate how much they know about BEP and running a simulated company. There is a notable difference between school and business-in the business world, having the wrong figures is a significant error and may cause the analyst to lose their job. In school, the student may get partial credit even if the answer is technically wrong. If it is a foundational cost accounting course and the test is about whether they can calculate BEP, the instructor may still give partial credit for a wrong answer with the right approach. In a capstone course, the instructor may overlook calculation transpositions or mistakes in order to assess how well the student justified their answer-that is, the second part of the prompt is what matters most for demonstrating mastery.

The nature of the question lends itself to utilizing the abundant data provided by the simulation. But, it also allows the student to demonstrate mastery of the concepts addressed in the capstone 
course. Providing both a quantified analysis and logical narrative using the data, the student is able to demonstrate mastery at the highest level of Bloom's taxonomy, evaluation.

\section{Report}

As described in the approach and using the equations for determining BEP, this example starts by calculating an answer to the first part of the prompt (Bloom's application level of thinking) and then provides a narrative in response to the second part (Bloom's synthesis level of thinking). Some of the data used in the narrative is not listed in the BEP data but is gathered from the class and the student's own spreadsheets. 
Figure 4.4 BEP Calculation for Example 3

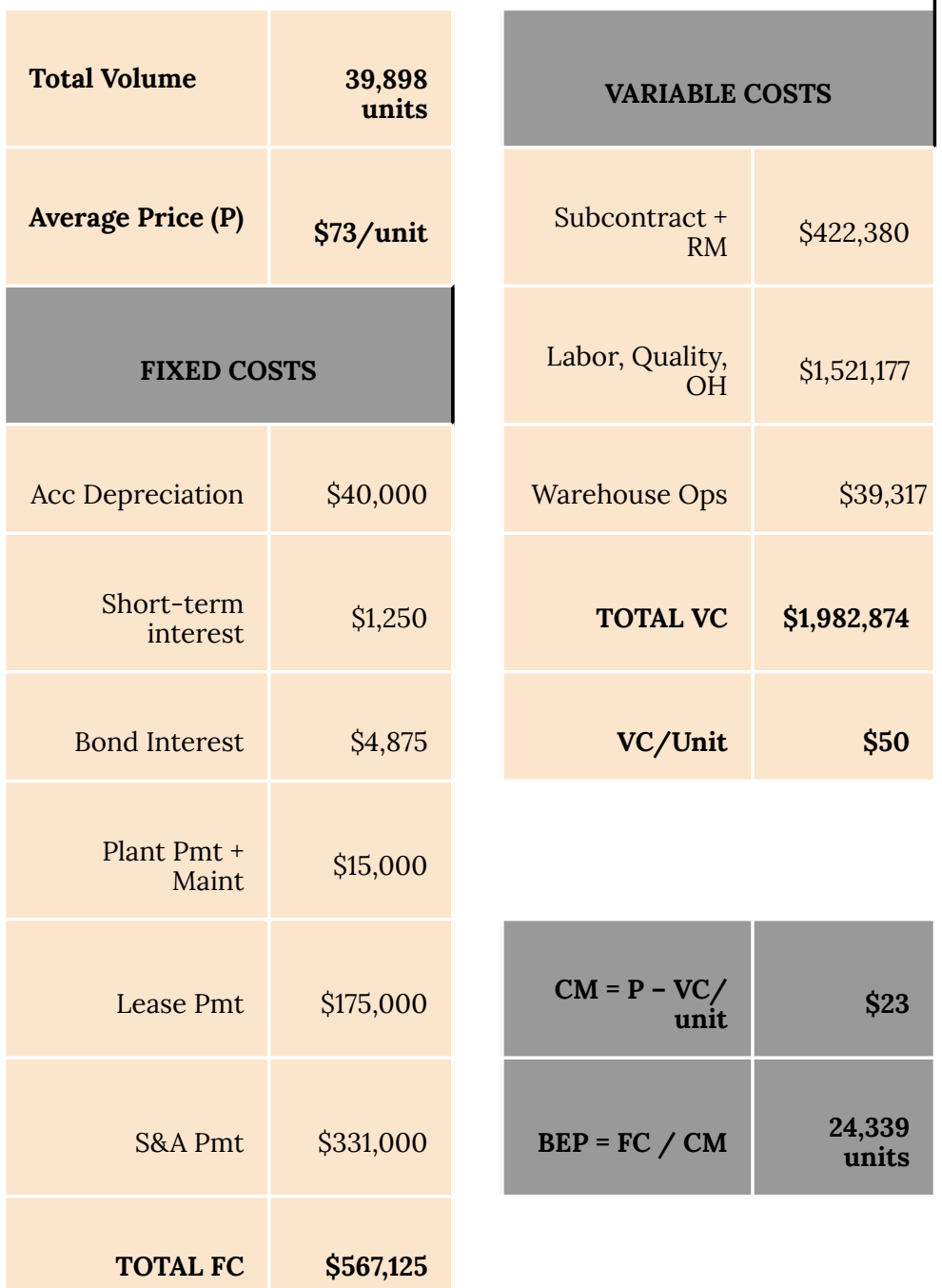

Our firm, Company \#3, finished Q8 in first place for the competition and very strong operational position with a BEP more than 15,000 units below our actual volume (39,898 units actual sales - 24,339 needed to break-even $=15,559$ units). Our cumulative 
health and resulting market power as evidenced by this BEP analysis provides us numerous options if we were to continue to operate the company in this simulation.

First, we could lower our prices to expand our market share. During Q8 our firm sold its product at $\$ 3 /$ unit below the average for the industry (even when excluding our own low price.) Only one company beat our price point in any of the three regions of operation; Company \#6 underpriced us by an average of $\$ 4 /$ unit. However, due to their product mix, they sold an average of less than $45 \%$ of our volume (average quarterly sales of 3908 versus our 8740 units) and finished the competition in seventh out of eight company teams. Even the second place finisher, Company \#1, struggled to maintain profitability while pricing their product higher than ours by an average of $\$ 1 /$ unit. At $19.4 \%$ of market share we are effectively controlling this industry; we lead second place Company \#1 by $2.4 \%$, and are the only firm with increasing market share at this point in the competition.

Next, we could increase our prices to improve our profit. Our $20 \%$ gross margin and $9.7 \%$ return on sales (ROS) leads the industry and is much stronger than second placed Company \#1, who finished Q8 with a $7 \%$ gross margin and ROS of $2.8 \%$. After eight quarters, this industry is proving to be unprofitable for most of the firms with only three out of eight still making a positive ROS. If the simulation allowed companies to be acquired or to go out-of-business (it does not), our industry would likely have been reduced by at least half in terms of the total number of competing firms. Our industryleading $\$ 55.02 /$ share price reflects our market power, operational excellence, and $12 \%$ return on owner's equity.

Lastly, we could implement a combination of the above options, use our strong contribution margin and cash reserve ( $\$ 544 \mathrm{~K}$ at the end of Q8) to expand our capacity, and continue to build a stronger operating advantage over our closest competitor, Company \#1. Overall at $\$ 23 /$ unit, the contribution margin of our product reflects a strength in our team's operational excellence and demonstrates a superior return on investor equity. The strong BEP demonstrated 
at the end of Q8 means we have flexibility to respond to whatever happens in the market and be masters of our own destiny.

\section{What if I Have to Present?}

Public speaking is one of the most common of anxieties; estimates range from 20-80 percent of all Americans have this fear. However, just like writing professional reports are common in business, so are presentations. Unlike writing a report, where you have time to think about what you want to write, you can edit for brevity and content, and you can discuss with colleagues about what to leave in and what to leave out, public speaking requires extensive planning followed by "throwing out the plan" once the presentation gets underway.

Making a successful business presentation requires just that, effective planning and the ability to think on your feet and adapt to the circumstances. The good news is, while a written report may leave you wondering if the intended audience ever read it, you get immediate feedback when you speak face-to-face with a small group. So, you'll know immediately if you performed well and sold your message. Because of this opportunity for active and dynamic feedback, if you are a good listener and observer, you can also make adjustments to improve your delivery "on the fly."

Assuming you have already conducted your analysis and identified what you want to say, the following will help you plan the presentation and deliver it optimally.

\section{Creating Effective Slides}

Your first or second slide should contain an outline of your presentation: 
- The outline slide should contain only the main points.

- The title of each slide should match your main points.

- Use the order shown in your outline for the rest of the presentation.

Plan for 1-2 slides per minute in your presentation:

- Include 4-5 points per slide, no more than 6-8 words per line.

- Include narrative in the speaker notes, not on the slide.

- Don't include slides that don't require narrative.

- Always include slide numbers-if you have to refer to a slide, you can use its number.

- Put slide content into a bulleted format.

- Write in key point form, not complete sentences.

- Sentence punctuation rules do not apply, but punctuation should be consistent.

- Prioritize clarity: use key words and phrases only, less is more.

Display one point at a time (slide animation, optional) to:

- Help the audience focus on what you are saying.

- Prevent the audience from reading ahead.

- Help you stay focused.

Use parallel construction:

- Slide titles should be parallel.

- Bullet items should be parallel.

- In group presentations, presenters' slide and topic organization should be parallel.

Use clear, simple fonts:

- Use at least an 18-point font. Larger is better, but don't crowd the slide.

- Use different size fonts for main points and secondary points. 
Varying by two sizes adds visible deviation.

- Use ALL CAPS only when necessary for emphasis. Use boldface or italics instead.

Use color effectively:

- Use a font color that contrasts sharply with the background.

- Use color to reinforce your organization (e.g., in a title)

- Occasionally use color to emphasize a point.

Use graphs, tables, and other visuals effectively:

- Data in graphs can be easier than raw data to comprehend and retain.

- Trends can be easier to visualize in graph form.

- Be sure the visuals are legible from the audience.

- Always title and label your graphs, provide a key if necessary.

Proofread your slides:

- Check for spelling, punctuation, and grammar errors.

- Check for repeated and extra words.

Use a strong conclusion:

- Your audience will most likely remember your last words.

- Summarize the main points of your presentation.

- Ask for Questions.

- Suggest action items/next steps.

Include a reference slide:

- Your last slide should be the reference slide.

- Cite your references according to APA formatting. 


\section{Delivering Presentations}

1. Open with a clear introduction of your purpose and topic.

2. Make eye contact with your audience throughout the presentation.

3. Remember who your audience is. Present the topic with the audience's needs in mind.

4. Use concrete, specific language. Avoid vague pronouns like "mine," "it," "they."

5. Do not read from the slides or your notes. Slides should briefly outline key points; fill in the details, expand, or add examples in your speech. Discuss topics; don't recite slides.

6. Know your material. Be prepared to answer questions about what is on your slide or what you say in your speech (not entire topic; just what you cover).

7. Display interest and enthusiasm. This is easier if you spend enough time with your source materials to find something of interest.

8. Speak clearly and at a comfortable pace, varying your tone and pitch as you would in a conversation. Add emphasis to the most important points, even repeat them to make your point.

9. Give readers enough time to read all content on each slide. Remember, the content on your slide should be very minimal.

10. Practice your delivery to check timing and to be sure you know what transitions you will use between ideas and slides.

11. Keep it simple but not simplistic. Visual elements (images) will help your audience stay engaged.

12. Provide transitions to guide audience from point to point. For example: "First", "For my next point", "As you can see", "In conclusion", etc.

13. Use professional transitions between speakers to create cohesiveness.

14. End with the most important takeaway points. For example: "In conclusion", "What you should take away", or "Remember". 


\section{Feedback and Grading}

To write is human, to edit is divine. Stephen King

The authors bounced back-and-forth about whether to include this section in the book. In the end, our desire to give students as much advantage as possible for demonstrating good writing and presentation skills by providing a peak behind the curtain won out. That is, we want to show you why your instructor may be so adamant about you writing better. At our educational institution, as with most universities, policies mandate instructors tell students how they'll be graded. However, the way that is communicated is often not specified and may remain a mystery in some courses.

Here we are devoting an entire chapter of the book to helping students understand their work from an instructor's perspective. We hope that, by knowing what they are looking for, you will craft your writing or presentation product to satisfy their expectations.

\section{Rubrics}

Employers value university credentials (degrees) because they are a relatively safe guarantee of an individual's ability to think at a pre-identified level about a specific topic. Universities, colleges, and schools use external accreditation institutions (like the Association to Advance Collegiate Schools of Business International, AACSB, which certifies the authors' college) to, among other things, certify to potential employers that its graduates meet a specific standardized curriculum appropriate for the business environment.

In turn, the faculty of the college determine how this curriculum of study will be allocated among the variety of course permutations to create the course catalog. This combination of external 
certification with faculty allocation is what makes one college's business education similar to, but unique from, any other college.

The allocation of curriculum requirements is divvied up among courses within the framework of the certification authority into learning outcomes. The accreditation organization dictates a certain amount of overlap, redundancy, and sequencing such that a high school graduate can ascend to a college graduate within a relatively predictable timeframe and a standardized body of knowledge. Therefore, while there is some flexibility in how an instructor will teach a subject, what topics are covered in that course is usually beyond the instructor's ability to alter.

Typically, the course syllabus is a result of the instructor's interpretation of his faculty assigned learning outcomes. The unique education, experiences, and abilities of the instructor reflect in what they chooses as a textbook, what they cover in the coursework, and how they structure your assignments. One course may be heavy in reading, another in problem solving, and so on. But ultimately, all students should in theory have comparable knowledge, skills, and abilities upon graduation from a business college.

\section{What is a Rubric?}

Merriam-Webster in part defines a rubric as "a guide listing specific criteria for grading or scoring academic papers, projects, or tests". As indicated by this definition, many instructors use rubrics for general assignment feedback. Before they even start the assignment, the rubric tells a student what they need to do and how their work will be evaluated.

Once the instructor begins assessing the student's work, it provides a uniform assessment of all student work over the breadth of a single assignment and expedites the delivery of feedback to students. Not only do rubrics ensure consistency across an entire 
course from one student to the next, from one section to the next, and from one term to another, they also combat potential inherent biases by guiding the assessment. When used rigorously, a rubric is the foundational standard by which a student's work is assessed and a grade is earned. In turn, rigorous use of rubrics removes the likelihood of both biases ("my instructor didn't like me") and chance ("I ended up in a really smart class").

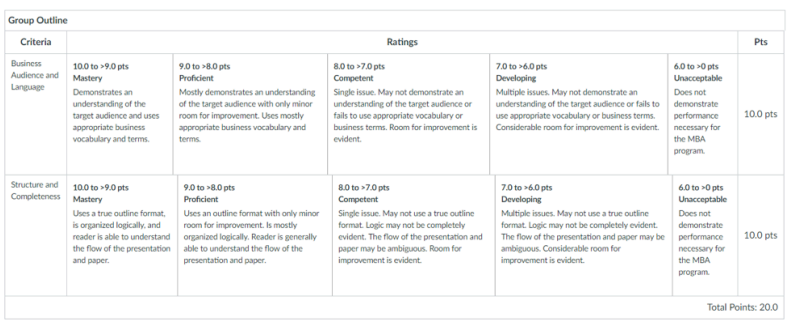

Figure 5.1

Sample of a

Rubric Used

for Scoring

Assignments

\section{What does this Mean?}

In its application, the instructor decides ahead of time how they will evaluate an assignment by creating rubric criteria, giving those criteria weights and levels, and determining how the assignment will fit in terms of importance to the course. High point values allow finer distinction in whole numbers when scoring. Unless the instructor weights assignments, these points relative to other assignment points can make a 1-point deduction a major or trivial matter. For example:

Missing 1-point on a 5-point assignment has the same impact for that assignment as does missing 20 on a 100-point assignment. 
A category with 5 assignments each worth 5-points, but weighted as $50 \%$ of the course total is a major matter even if compared to 5 other assignments each worth 100-points each.

\section{Why Understand the Rubric?}

It is essential to understand the rubric before beginning an assignment. The rubric will show the specific areas which the student will be graded on for a specific assignment, and these categories break down what a student needs to do to receive any given score.

When an instructor designs a course, they start with the course learning outcomes or LOs. Instructors teach to their strengths. That is, if your instructor obtained a Phd from a school known for its rigor in research, wrote their dissertation on a narrowly defined topic, and now publishes extensively on that same topic, expect their course to borrow heavily from this discipline and use assignments that explore this body of knowledge. However, if your instructor is a practitioner who worked extensively in industry without a terminal degree, expect your course to rely heavily on their real world experiences and to offer up similarly related assignments.

Taken together, the assignment prompt and its accompanying rubric, provide a blueprint for what the instructor expects and how they will grade or score your work. Taking the time to understand how your assignment will be assessed will provide a clear plan for how to best complete the assignment. 


\section{Understanding Feedback}

After receiving a grade and in order to improve for the next assignment, you need to understand why you received a particular grade. Grading styles can vary tremendously among instructors, but the responsibility of understanding their grade and learning from their mistakes always falls on the student. Review their feedback in context of both the original assignment prompt and the rubric. Oftentimes, a low score on an assignment is a result of not following the instructions or providing specific elements of the assignment that were requested in the prompt or evaluated in the rubric.

\section{Key to Common Markups (and how to fix them)}

As stated above, feedback and grading styles vary from instructor to instructor. Below is one example of a style of feedback-a list of common errors in writing and explanations for how to fix the error. Instructors may choose to abbreviate on the paper itself and use the list below, or similar, for more detailed explanations. These markups are, in no way, standardized in format. However, the issues they reflect are common in terms of what most instructors look for when giving feedback.

Some instructors may simply place a checkmark in the margin or color-code parts of a student's report with a highlighter to communicate what was done well and what needs to be improved. For example, green highlights can be used to identify "wins" in the writing-things that are on target or particularly well done; orange highlights can represent "misses" or "errors-things that are incorrect or problematic. Research on student feedback indicates when an instructor gives abundant feedback and corrects every 
error on the report, she is actually doing a disservice for the student. This research indicates that identifying where an error exists forces the student to self-assess and correct. This practice creates stronger and more sustained learning.

- Logic Error (LE) - an error in reasoning that renders the argument invalid. Often an unsubstantiated assertion that is delivered with a conviction that makes it sound as though it is fact. It may draw a false conclusion or misuse evidence or language.

- Use linear, cause-effect thinking without skipping steps;

- Base arguments on inductive (an accumulation of examples) or deductive (a breaking down of facts) reasoning;

- Avoid manipulating the evidence of your observations or citations to match your analysis. Instead, when the evidence points in a different direction, change your conclusion.

- Missing Citation (MC) - potentially plagiarism, it means stating a fact without providing a source for the fact. While it is okay to state facts from the case or a lecture without citing the source, apart from either of these, a citation is required.

- Missing Evidence (ME) - when there is an opportunity to cite supporting evidence but such evidence is omitted. See also LE and MC.

- Using adjectives (e.g., big, large and very) typically require some data to make them relevant;

- Look for opportunities to cite supporting evidence from the case;

- Use external sources (if available) to support arguments.

- Passive (P) - technically, this is when the subject, not the object, receives the action of the verb in a sentence. Often, the agent performing the action is not identified. Passive voice often leads to very wordy or evasive writing. 
- Write in terms of a subject, performing an action on an object;

- Avoid placing the action (verb) after the agent (noun) performing the action.

- Redundant (R) - a form of wordy writing that uses the same word, phrase or concept repeatedly within a sentence, a paragraph or a case brief.

- Use variety in your writing; but

- Avoid using synonyms you don't understand (see word choice).

- Sentence Fluency (SF) - the quality of consistently applying skill correctly in the manner of one well-practiced at it. Found when speaking a written passage out loud is difficult.

- Write how native speakers write;

- Write how native speakers talk;

- Avoid overly informal or casual writing that sounds too conversational or casual;

- Be aware of grammar errors such as subject-verb agreement and plural and singular pronouns.

- Verb Tense (VT) - verbs show action in English writing and convey past, present and future tenses as in written - writing - will write. Use the proper tense to describe an action on the object in a sentence.

- Xiao has written;

- Xiao is writing;

- Xiao will write.

- Word Choice (WC) - beyond verb tense, word choice is using a word out of place or in the wrong context.

- Choose understandable, specific and precise words;

- Avoid overused and obsolete words.

- Word Form (WF) - choosing the wrong form of the word, for example, using an adjective instead of a noun.

- Become familiar with different parts of speech, and how 
they are used;

- Check your work to make sure you're using verbs as action words, nouns as subjects and objects, and adjectives as descriptive words;

- Adjectives and adverbs are easily confused. An adverb will answer the question "how is something done?"

- Wordy (W) - verbose, using more words than is necessary. Often it happens when using many general or vague words instead of the correct, professional term - such as, "to improve the differences between how many units sold for each machine used" means the same as "improved machine productivity".

- Whenever possible, delete nonessential words from your writing;

- Avoid using long words when there are good short ones available.

\section{Resources For Getting Better}

There are ample resources online for helping learners improve their skills and increase the rate of their learning. Both foreign and domestic students can benefit from the resources below.

- Learning Express - access via the course LibGuide. This is a subscription service provided through your student fees and offers a variety of online resources for writing, career, and other topics.

- Everyone's an Author by Lunsford, Ede, Moss and Papper, 2012, ISBN-13: 978-0393912012, book available in OSU Bookstore or Amazon.

- Purdue Online Writing Lab - a popular and useful writing resource of Purdue University.

- Grammar Resources - Towson University writing support. 
- Don't just practice writing, be focused in your practice! Read business-related periodicals to get familiar with the style and specialized language of business. Consider listening to popular business stories as well. Most of these sources also offer free content to your mobile device. These are just a few common suggestions, many others are available.

- Wall Street Journal

- Fortune Magazine

- Harvard Business Review

- CNN Money

\section{Exercises for Getting Better}

\section{Avoiding plagiarism}

Answer the following question in a paragraph:

What is plagiarism and what are the common causes of it?

Key: See Keeping writing honest and avoiding plagiarism section 


\section{Writing a counterargument}

Look at the counterargument paragraph from a student's writing below and do the following.

Identify where the author turns against and turns back to their argument?

How do you know?

What might the student's thesis be?

How could you improve this paragraph?

Admittedly, the vegetarian diet can be beneficial for some individuals. It is true that for people who have health problems, such as high blood pressure, a diet full of vegetables alleviate some of their health issues. However, meat provides people with various nutrients which vegetables and fruits cannot give, allowing the general population to lead a much healthier lifestyle if they do consume meat. More importantly, people's dietary habits vary across regions: for instance, people living near the Arctic tend to regard meat as their main dish, as vegetables are difficult to grow in that area.

Key:

1. The author turns against the original argument in the first sentence after "admittedly" by acknowledging the other side of the argument.

2. We know this because "admittedly" signals the turn against, and "however" signals the turn back, which is followed by support for the thesis. 
3. The thesis would be "a diet containing meat is healthier than a vegetarian diet" or something similar.

4. Structurally, this is a fine paragraph, but there is a lack of support for both the turn against and turn back to the thesis. The author would have a stronger argument by including examples of nutrients which cannot be found in fruits and vegetables and also developing the example about people in the Arctic. Currently, it provides little support because it is so brief.

\section{Levels of thinking - understanding the assignment requirements}

Look at the two assignment prompts below and answer the questions.

1. What are the key verbs in each prompt?

2. How do these words help you know how to approach the prompt?

3. According to Bloom's Taxonomy, what level of thinking does the prompt require?

Describe the complete industry value chain for the cereal manufacturing business. What role does each sector (primary, secondary, tertiary) play in getting cereal from farmland to table?

Identify one of Company X's strengths, weaknesses, opportunities, or threats. Then, make a persuasive argument for how that factor will make the biggest impact on the firm's success.

Key: The key verb in the first prompt is "describe", and requires a student to provide a description of the cereal manufacturing 
process. "Describe" falls under the lowest category of Bloom's Taxonomy. This prompt does not require more than a basic and descriptive response. In the second prompt, the keywords are "identify" and "make a persuasive argument". Like "describe", "identify" falls under the lowest level, but this prompt also requires students to "persuade", which is the highest level of Bloom's Taxonomy. In this case, writing a counterargument could be part of persuading.

\section{Transition words}

Look at the paragraphs below, which are in response to the prompt: Describe the complete industry value chain for the cereal manufacturing business. What role does each sector (primary, secondary, tertiary) play in getting cereal from farmland to table?

Both paragraphs contain the same content but they have different transition words. Look at the words in red in each paragraph. As a whole, which paragraph has a better flow?

The primary sector business provides the raw materials for the manufacturers. First, farmers and growers must purchase seeds of wheat, oats, corn and rice from seed suppliers then plant and harvest their crop. Second, they supply wheat, oats, corn and rice to cereal manufacturers. Third, the cereal manufacturer needs to get sugar, cocoa and edible colorings from other suppliers. Also, paper mills provide manufacturers with cardboards and envelopes. After the grains, sugars and paper products are gathered and transported to the factory, the products are produced and assembled, as 
the first stage in the secondary sector.

The primary sector business provides the raw materials for the manufacturers. In order to do this, farmers and growers must purchase seeds of wheat, oats, corn and rice from seed suppliers then plant and harvest their crop. After harvest, they supply these grains to cereal manufacturers. Meanwhile, the manufacturer needs to get sugar, cocoa and edible colorings from other suppliers. As for the packaging, paper mills provide manufacturers with cardboards and envelopes. Once the products are gathered and transported to the factory, they are produced and assembled, as the first stage in the secondary sector.

Key: The second paragraph is stronger overall. This is because there are more advanced transitions used. In the first paragraph, the use of "first" is very basic, whereas "In order to do this" connects connects refers back to "provides the raw materials" with the use of "this". Similarly, use of "second" is very basic while "after harvest" connects back to the sentence before it. In that same sentence, it is not necessary to list the grains, as is done in the first paragraph. Using "these" grains is a clear substitute. When comparing "also" and "as for the packaging", the later provides a nice transition to the next topic-packaging. In the last sentence, it is not necessary list the names of all the products again, "products" will do. 


\section{Grammar, Word Choice and Writing Concisely}

Rewrite the sentences below to make them clear, concise, and grammatically correct.

1. Katarina should talk to managers to shape their ideas to understand if these changes have to happen and what is probably going to happen after these changes and what is missing from the plan.

2. By analyzing the case we can know that workforce planning possibly can make the biggest impact on Company X's success.

3. The flat organizational structure in Company $\mathrm{X}$ enables employees to communicate with management directly, helping the task distribution and feedback become more precisely and efficiently.

4. The old operating system is not able to supply data that is well-organized to employees, so they cannot accurately foresee and make precise preparations to the problems.

5. From the SWOT analysis, it can clearly be seen that Company X's strengths are the way its supply chain is efficient and it how loyal it's suppliers are.

Key: Possible answers.

1. She should get the management's opinion to determine whether the changes are necessary, the potential results of the changes and what the plan lacks.

2. Workforce planning can have the greatest impact on Company 
X's success.

3. Company X's flat organizational structure enables direct communication, helps task distribution and allows for precise and efficient feedback.

4. The old operating system fails to supply well-organized data to employees, which doesn't allow for accurate forecasting and anticipation of problems.

5. The SWOT analysis shows that Company X's strengths are its efficient supply chain and supplier loyalty. 


\section{Acknowledgements}

This textbook project was made possible by a grant from the Oregon State University (OSU) Open Textbook Initiative and the authors would like to thank Dianna Fisher and later Shannon Riggs for their guidance and assistance in its creation.

The foundation for the project started long before the textbook became a reality. John attempted a similar textbook project twice with V.T. Raja and Rene Reitsma, both faculty in OSU's College of Business in 2010 and 2011, but it did not make it out of the starting blocks. Still, these two gentlemen persisted and generously provided a review of the written material before publication.

Ted Patterson, also an associate professor in the OSU College of Business, importantly lent the authors access to four video writing workshop lectures (one is used with permission in Chapter 3 ) that helped shape and inform our work.

Jason Marquart, from INTO OSU graciously shared his thesis statement video, which is used in the Standard Essay Template section.

Rochelle King, from INTO OSU put many hours into improving this manuscript. Her knowledge of language teaching and grammar was a very helpful addition.

Lucia Stone, from INTO OSU helped with the detailed editing of the document. We are very thankful for her keen eye and ability to catch what we had missed.

Lastly, and certainly not least, two cracker jack teaching assistants, Hailee Schroeder and Katharine Satak for miscellaneous projects to make this book coherent. 


\section{About the Authors}

In 2009, John Morris transitioned from a three decades long career in private industry to teach at OSU; his first course incorporated the university's Writing Intensive Course (WIC) requirement, for the College of Business. As a stipulation of its accreditation process, AAC\&U requires that each college have a WIC that teaches students how write in the profession. Having worked extensively with recent college graduates in private industry, John had some very specific ideas about what was needed to write for business, but he found little in existence in the way of universal business writing standards beyond academic writing guides. During the interim nine years of teaching WIC, a variety of undergraduate and graduate courses, and collaborating with other business instructors and professors, he developed a variety of job aids to help students write for business.

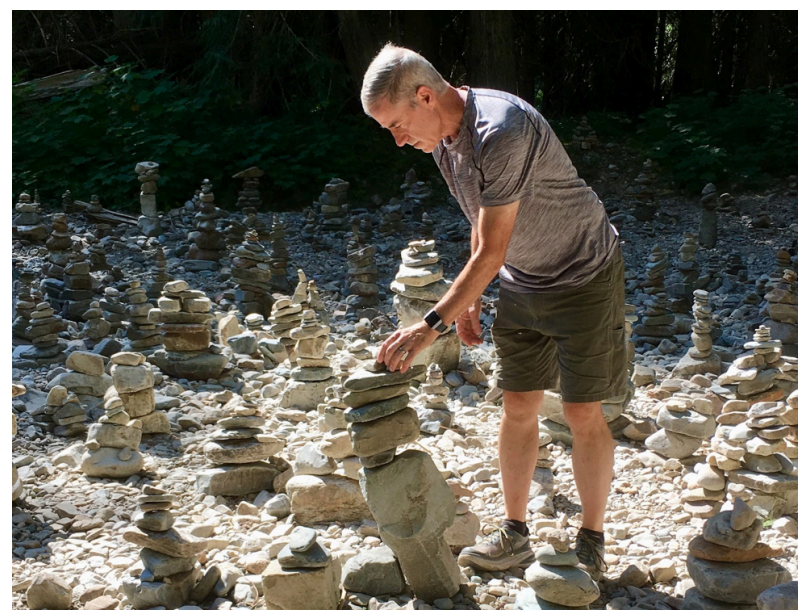

John building cairns.

Julie Zwart is an instructor in INTO Oregon State University's Graduate Pathway program. The Pathway program was established in 2008 to provide language, culture, and academic support for international students as they transition into their masters 
programs at OSU. Julie began teaching at INTO OSU in 2014, and shortly after worked on a project to redesign a foundational MBA pathway course, which is how she met John. Later she worked with him as co-instructor in the MBA Pathway teaching writing and analysis. Over the course of working together and assessing the needs of students in terms written communication for business purposes, the two undertook creating this writing textbook.

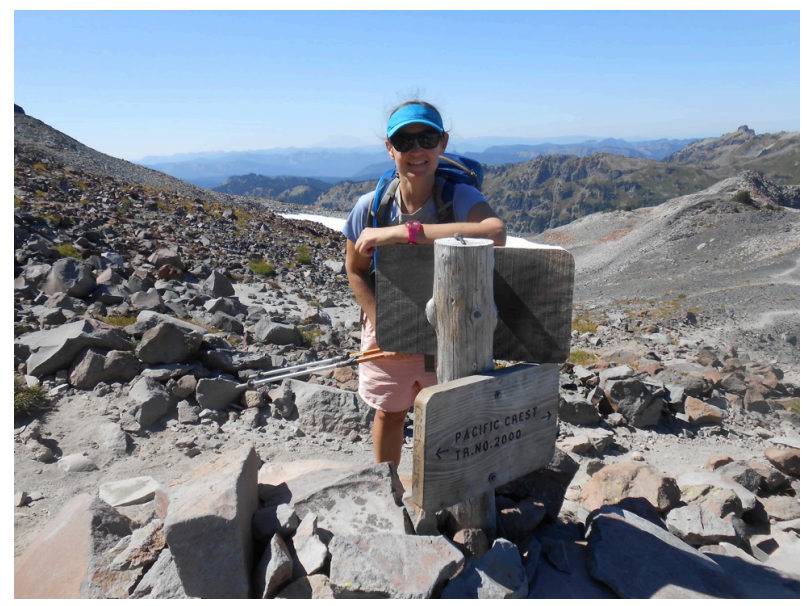

Julie hiking on the Pacific Crest Trail 


\section{Works Cited}

There are no secrets to success. It is the result of preparation, hard work, and learning from failure. Colin Powell

"Active Voice Adds Impact to Your Writing." Yourdictionary.com. n.d. Accessed 2018. http://grammar.yourdictionary.com/style-and-usage/ active-voice-adds-impact-to-your-writing.html

"Break-Even Analysis." Investopedia. n.d. Accessed August 2018. https://www.investopedia.com/terms/b/breakevenanalysis.asp

"Comparison Of Business And Academic Writing." Yourdictionary.com. n.d. Accessed July 2018. http://grammar.yourdictionary.com/writing/ comparison-of-business-and-academic-writing.html

"Context." Merriam-Webster.com. n.d. Accessed September 12, 2018. https://www.merriam-webster.com/dictionary/context

"Counterargument." Harvard College Writing Center. n.d. Accessed August 2018. https://writingcenter.fas.harvard.edu/pages/counter-argument

Drown, Eric. "Writing As a Recursive Process 1." Uneportfolio. October 3, 2016. http://ericdrown.uneportfolio.org/2016/10/03/writing-as-arecursive-process-1/

"Increase." Merriam-Webster.com. n.d. Accessed August 2018. https://www.merriam-webster.com/dictionary/increase

Hagy, Jessica. "Practice Makes Legacy". July 20,2018. http://thisisindexed.com/2018/07/practice-makes-legacy/

Jshabatu. "Using Bloom's Taxonomy to Write Effective Learning Objectives." Teaching Innovation and Pedagogical Support. March 19, 2018. https://tips.uark.edu/using-blooms-taxonomy/

Murray, Donald Morison. A Writer Teaches Writing. 2nd ed. Boston: Houghton Mifflin, 1985.

Nicas, Jack. "Apple Is Worth $\$ 1,000,000,000,000$. Two Decades Ago, It Was Almost Bankrupt." The New York Times. August 2, 2018. https://www.nytimes.com/2018/08/02/technology/applestock-1-trillion-market-cap.html 
"Plagiarize." Merriam-Webster.com. n.d. Accessed August 2018. https://www.merriam-webster.com/dictionary/plagiarize

"Profitability of UK continental shelf companies increased slightly but remains low by historical standards." Office for National Statistics. July 13, 2017. https://www.ons.gov.uk/economy/nationalaccounts/ uksectoraccounts/bulletins/profitabilityofukcompanies/ jantomar2017\#profitability-of-uk-continental-shelf-companiesincreased-slightly-but-remains-low-by-historical-standards

"Securing a market leading future through SWOT analysis. A Hewden case study." Business Case Studies. n.d. Accessed September 2018. https://businesscasestudies.co.uk/hewden/

Stossel, Scott. "Performance Anxiety in Great Performers." The Atlantic. February 4, 2014. Accessed April 8, 2017. https://www.theatlantic.com/ magazine/archive/2014/01/what-hugh-grant-gandhi-and-thomasjefferson-have-common/355853/

Technical Communication. 13e by Lannon \& Gurak. Pearson Higher Ed publishers. 2008. 


\section{Creative Commons License}

This work is licensed by John Morris and Julie Zwart (C2018) under a

Creative Commons Attribution-NonCommerical-Share Alike 4.0 International License (CC BY-NC-SA)

You are free to:

Share - copy and redistribute the material in any medium or format

Adapt - remix, transform, and build upon the material The licensor cannot revoke these freedoms as long as you follow the license terms.

\section{Under the following terms:}

Attribution - You must give appropriate credit, provide a link to the license, and indicate if changes were made. You may do so in any reasonable manner, but not in any way that suggests the licensor endorses you or your use.

NonCommercial - You may not use the material for commercial purposes.

ShareAlike - If you remix, transform, or build upon the material, you must distribute your contributions under the same license as the original.

No additional restrictions - You may not apply legal terms or technological measures that legally restrict others from doing anything the license permits. 


\section{Recommended Citations}

\section{APA (7th)}

Online:

Morris, J., \& Zwart, J. (2018, January 1). Business Writing Style Guide.

https://open.oregonstate.education/businesswriting/.

Print:

Morris, J., \& Zwart, J. (2018). Business Writing Style Guide. Oregon State University.

\section{APA (6th)}

Online:

Morris, J., \& Zwart, J. (2018, January 01). Business Writing Style Guide. Retrieved [Retrieval date e.g. January 1, 2021], from 
https://open.oregonstate.education/businesswriting/

Print:

Morris, J., \& Zwart, J. (2018). Business Writing Style

Guide. Corvallis, OR: Oregon State University.

\section{MLA (8th)}

Online:

Morris, John, and Zwart, Julie. Business Writing Style Guide. 1 Jan. 2018, https://open.oregonstate.education/ businesswriting/.

Print:

Morris, John, and Zwart, Julie. Business Writing Style Guide. Oregon State University, 2018. 


\section{$\operatorname{MLA}\left(7^{\text {th }}\right)$}

Online:

Morris, John, and Zwart, Julie. "Business Writing Style Guide." 01 Jan. 2018. Web. [Retrieval date e.g. 1 Jan. 2021].

Print:

Morris, John, and Zwart, Julie. Business Writing Style Guide. Corvallis: Oregon State U, 2018. Print.

\section{Chicago}

Online:

Morris, John, and Julie Zwart. "Business Writing Style Guide," January 1, 2018. https://open.oregonstate.education/businesswriting/.

Print:

Morris, John, and Julie Zwart. Business Writing Style Guide. Corvallis, OR: Oregon State University, 2018. 


\section{Versioning}

This page provides a record of changes made to this publication. Each set of edits is acknowledged with a 0.01 increase in the version number. The exported files, available on the homepage, reflect the most recent version.

If you find an error in this text, please fill out the form at bit.ly/ 33cz3Q1

\begin{tabular}{|l|l|l|l|}
\hline Version & Date & Change Made & Location in text \\
\hline 0.1 & MM/DD/YYYY & & \\
\hline 0.11 & $08 / 06 / 2020$ & $\begin{array}{l}\text { Links to external } \\
\text { sources updated }\end{array}$ & All \\
\hline 0.12 & $11 / 23 / 2020$ & $\begin{array}{l}\text { Updated } \\
\text { Resources For } \\
\text { Getting Better }\end{array}$ & $\begin{array}{l}\text { Feedback and } \\
\text { Grading (Ch. 5) }\end{array}$ \\
\hline & & & \\
\hline
\end{tabular}

